\title{
UCRL-CR-151434
}

IA WAE NCE TIULAMCRE WATIONAL LAEDAATCAY

\section{Tests of the Contamination Analysis Unit, Phase 2}

M. Meltzer, $P$, Daley

January 21, 2003 


\section{DISCLAIMER}

This document was prepared as an account of work sponsored by an agency of the United States Government. Neither the United States Government nor the University of California nor any of their employees, makes any warranty, express or implied, or assumes any legal liability or responsibility for the accuracy, completeness, or usefulness of any information, apparatus, product, or process disclosed, or represents that its use would not infringe privately owned rights. Reference herein to any specific commercial product, process, or service by trade name, trademark, manufacturer, or otherwise, does not necessarily constitute or imply its endorsement, recommendation, or favoring by the United States Government or the University of California. The views and opinions of authors expressed herein do not necessarily state or reflect those of the United States Government or the University of California, and shall not be used for advertising or product endorsement purposes.

This work was performed under the auspices of the U. S. Department of Energy by the University of California, Lawrence Livermore National Laboratory under Contract No. W-7405-Eng-48. 
Final Report on

Tests of the Contamination Analysis Unit, Phase 2

\author{
ATK Thiokol Propulsion \\ and \\ Lawrence Livermore National Laboratory \\ Work Performed by Lawrence Livermore National Laboratory \\ for \\ ATK Thiokol Propulsion \\ Purchase Order/Contract No. M8SR020-2 \\ Thiokol Project Test Plan PTP 0467 \\ Prepared by \\ Michael Meltzer and Paul Daley \\ Lawrence Livermore National Laboratory
}




\section{Executive Summary}

Results are reported for a project testing the capabilities of a mass spectrometer-based system for analyzing in-situ organic compounds on a variety of substrates. The system, which was built and operated at Lawrence Livermore National Laboratory (LLNL), is termed a Contamination Analysis Unit (CAU) and employs vacuum and thermal desorption of surface residues, followed by ionization and analysis with a Leybold Inficon Transpector mass spectrometer. The CAU was employed in this study to examine soils, cleaner residues, and substrates on Space Shuttle Reusable Solid Rocket Motor (RSRM) components. Project work was supported by ATK Thiokol Propulsion. Major project objectives include:

1. Determine residual propellant and liner components with the CAU after test coupons have been cleaned.

2. Determine if the CAU can detect solvent that has soaked into NBR insulation material, and if possible, determine the time following solvent application during which the cleaning agent is detectable.

3. Test CAU capabilities for analyzing non-flat surfaces on the inside and outside surfaces of the RSRM (12-foot diameter), and nozzle throat housing surfaces (5-foot diameter).

4. Determine if solvent extraction and gas chromatography (GC) approaches are able to enhance the surface analysis data available through use of the mass-spectrometerbased CAU.

5. Determine the CAU s detection limit for various soils and cleaners.

6. Determine if contact of both Viton and silicon O-rings with critical substrates will result in any visual evidence of the contact, when observed under black light.

7. Demonstrate CAU viability during routine Thiokol manufacturing operations.

Results are summarized below:

Task 1: Propellant/Liner Component Analysis. The purpose of this task was to determine if the CAU could detect Thixcin E, HB polymer (PBAN), ECA (D. E. R. 331 Epoxy Resin), ERL-0510 (Araldite MY0510), and paraffin. None of these compounds were amenable to analysis by the CAU.

Task 2: NBR Insulation Solvent Absorption Tests. The goal of this task was to determine if the CAU could detect solvents that had soaked into NBR. After applying lonox, PF Degreaser, or Bioact 145 to NBR surfaces, wiping the surfaces dry, and allowing the surfaces to air-dry for 30 minutes, all of these solvents were easily detected with the CAU. A further goal was to evaluate how long after application TCA and PF 
Degreaser were detectable. In this experiment, both target ions and total system pressure were monitored. TCA was detected by several ions and system pressure for at least 100 hours following application; PF Degreaser was detectable by some ions for over 300 hours after application, although the time course of apparent detectability was more complex than for TCA. In all cases, treated panels and untreated controls were measured, to account for any drift in instrument response.

Task 3: Curved Surface Analysis. Using the CAU s single O-ring inlet, sufficient vacuum was achieved to allow the analysis of both inner and outer surfaces of stainless steel plates of 5-foot and 12-foot diameter curvatures.

Task 4: Solvent Extraction and Gas Chromatography (GC) Analysis. A hand-held, high sensitivity gas chromatograph developed at LLNL for gas analyses was tested and demonstrated potential as a surface analysis tool capable of detecting trace concentrations of contaminants of interest in RSRM operations.

Task 5: Detection Limit Studies. Detection limits for soils and solvents that were amenable to analysis with the CAU were determined. The solvents studied, and their detection limits, included Bioact 145,5 g/ $\mathrm{cm}^{2}$; Ionox, $0.5 \mathrm{~g} / \mathrm{cm}^{2}$; and PF Degreaser, $0.2 \mathrm{~g} / \mathrm{cm}^{2}$. The soils studied, and their detection limits, included HD-2 grease, 0.5 $\mathrm{g} / \mathrm{cm}^{2}$; Permacel P-34 tape adhesive, $5 \mathrm{~g} / \mathrm{cm}^{2}$; Permacel P-422 Teflon tape adhesive, 2 $\mathrm{g} / \mathrm{cm}^{2}$; yellow tape adhesive, $1 \mathrm{~g} / \mathrm{cm}^{2}$; DC 90-006-02B, $30 \mathrm{~g} / \mathrm{cm}^{2}$; TIGA-321 B, 2 $\mathrm{g} / \mathrm{cm}^{2}$; TIGA-321 A, $17 \mathrm{~g} / \mathrm{cm}^{2}$; and PR1422B, $8 \mathrm{~g} / \mathrm{cm}^{2}$.

Task 6: Black Light Testing. No detectable residues, as determined with black light, were evident on stainless steel plates that had contacted Viton, general purpose silicone, or high temperature silicone O-rings during routine operation of the CAU. However, these (bulk) materials did not fluoresce. Thus, black light testing is not appropriate to determine their residues. The CAU successfully detected $1 \mathrm{~g} / \mathrm{cm}^{2} \mathrm{HD}-2$ grease on a stainless steel plate; black light testing could not detect HD-2 contamination at this concentration. The CAU detected $1 \mathrm{~g} / \mathrm{cm}^{2}$ of yellow tape adhesive on a stainless steel plate; black light testing could not detect this adhesive below a concentration of $100 \mathrm{~g} / \mathrm{cm}^{2}$.

Task 7: CAU Viability During Routine Manufacturing Operations. The CAU demonstrated the ability to detect trace amounts of HD-2 grease on bare-metal RSRM case material, on witness panels, and on NBR insulation material. The accuracy of the witness panel reading was probably affected by the period of time since CAU calibration and the effects of transportation from LLNL to Thiokol. 


\title{
Final Report \\ Tests of the Contaminant Analysis Unit (CAU), Phase 2
}

\author{
Prepared by \\ Michael Meltzer and Paul Daley ${ }^{1}$ \\ Lawrence Livermore National Laboratory \\ Work Performed for Thiokol Propulsion Under \\ Purchase Order/Contract No. M8SR020-2 \\ In accordance with Thiokol Project Test Plan PTP 0467
}

\section{Project Overview}

Lawrence Livermore National Laboratory (LLNL) has developed a mass spectrometerbased system that measures organic surface residues in situ. This system, called the Contamination Analysis Unit (CAU), can detect and quantify a variety of volatile surface residues on a range of different substrates. Residue samples are removed from the substrate using a combination of vacuum and thermal desorption, and are then ionized and quantified by a quadrupole mass spectrometer.

The current effort (Phase 2) was carried out in accordance with Thiokol Project Test Plan PTP-0467. A first phase of tests was completed under PTP-0327 and the results reported in TWR-75385. The Phase 2 test plan, PTP-0467, is a follow-on to PTP-0327, and was conducted in order to more fully determine the capabilities of the CAU.

This report summarizes experiments in which the CAU was evaluated for application in reusable solid rocket motor production scenarios. The report has been ordered by the tasks requested by ATK Thiokol Propulsion Testplan PTP-0467.

Project tasks included the following:

1. Determine the amount of residual propellant and liner components with the CAU after coupons have been cleaned.

2. Determine if the CAU can detect solvent that has soaked into NBR.

3. Test the capabilities of the CAU for analyzing non-flat surfaces on the inside and outside of the 12-foot diameter Reusable Solid Rocket Motor (RSRM) and 5-foot diameter nozzle throat housing surfaces.

\footnotetext{
'Special thanks to Carolyn Koester of LLNL's Chemistry \& Material Sciences Directorate for input to many phases of this project.
} 
4. Determine if solvent extraction and gas chromatography (GC) approaches are able to enhance the surface analysis data available through use of the mass-spectrometerbased CAU.

5. Determine the CAU s detection limit for various soils and cleaners.

6. Determine if contact of both Viton and silicon O-rings with critical substrates will result in any visual evidence of the contact, when observed under black light.

7. Demonstrate CAU viability during routine manufacturing Thiokol manufacturing operations. This effort was originally projected to include three one-week visits to Utah in 2000 to analyze surfaces during routine FSM-9 manufacturing and three additional one-week visits to Utah in 2001during FSM-10 PSA manufacture. These two tasks were compressed into one that was conducted at Thiokol during 2000.

\section{Design of CAU}

The CAU consists of a commercial Transpector mass spectrometer (Leybold Inficon, Inc.) interfaced, via a gate valve, to a thermal desorption sample inlet. A heater, operating in vacuum $\left(\sim 10^{-5}\right.$ torr $)$ and at temperatures ranging from ambient to $250 \mathrm{C}$ (about $480^{\circ} \mathrm{F}$ ), is used to volatilize the organic surface contaminants being analyzed. After volatilization, the contaminants are drawn into the source of the Transpector by vacuum, ionized, and mass analyzed. The CAU maximum operating temperature is within Thiokol temperature requirements for steel and painted hardware $(500 ; \mathrm{F})$ per SRB Thermal Design Data Book SE-019-068-2HAS Rev. E March 1991, Table 4.0.1.1, page 4.0.1-2.

The CAU can detect only volatile/semi-volatile compounds. In order to be analyzed by the CAU, analytes must be sufficiently volatile to be removed by vacuum and thermal desorption from the surface being examined. In addition, the analyte (and the surface) must not be degraded by temperatures of $250 \mathrm{C}$. Surfaces that outgas significantly (for example, EPDM rubber) or that powder easily (for example, carbon cloth phenolic) cannot be analyzed by the CAU. These substrates will contaminate the CAU, decreasing its sensitivity and requiring it to be disassembled and cleaned. In addition, dust from materials will damage the CAU s turbopump.

Between measurement sessions, the CAU is kept evacuated, with a polished steel panel covering the desorption nose of the unit. Prior to data collection, thermal desorption runs are performed on the blank panel to ensure uniform, low background for measurements. Ions for materials to be tested during the subsequent session are usually chosen for monitoring during these preparatory blank runs. Mass accuracy was checked periodically with perfluorotributylamine (PFTBA) at masses 69,100,131 and 164. The latter masses were always within 0.2 AMU of their targets.

Results of project work are discussed below. 


\section{Task 1: Propellant/Liner Component Analysis}

The goal of this task was to determine if the CAU can detect volatile organic components of the propellants and liners used by Thiokol in its TP-H1148 propellant system. The reason for analyzing only the volatile organic fraction of the propellant was to avoid any dangers related to shipping and analyzing potentially explosive components of the propellant.

The materials studied included the propellants ECA (D. E. R. 331 Epoxy Resin) and HB polymer (PBAN), and the liners ERL-0510 (Araldite MY0510) and Thixcin ${ }^{\mathrm{D}} \mathrm{E}$. Later, paraffin was added to the list of soils to be studied.

\section{Experimental Procedure}

A small amount of each soil was applied to a smooth, stainless steel plate. The CAU was heated at a rate of $0.5 \mathrm{C} / \mathrm{min}$ from ambient temperature to $200 \mathrm{C}$ and the instrument was scanned continuously from 42 to 150 AMU to determine if any signals from the relevant soil could be detected. The CAU was operated with the single (blue silicone) O-ring configuration.

\section{Results}

None of the above compounds were amenable to analysis by the CAU. Detailed explanations follow.

ECA (D. E. R. 331 Epoxy Resin) is a reaction product of bisphenol A and epichlorhydrin. We had hoped that as the compound was heated, small fragments of the polymer (or its starting materials) would volatize and be detected with the CAU. However, no signal from ECA could be detected.

$\mathrm{HB}$ polymer (PBAN) is a polybutadiene, acrylic acid, acrylonitrile polymer with a molecular weight of approximately $6000 \mathrm{~g} / \mathrm{mol}$. Thus, because of its high molecular weight and low volatility, we did not expect that HB polymer itself would be detected by the CAU. Thinking that, as the compound was heated, we might be able to detect smaller fragments of the HB polymer as it decomposed under heating, we attempted to analyze this material with the CAU. No signal from HB polymer was detected. This is consistent with previous work that suggested that detection limits for HB polymer were so poor as to prevent the use of the CAU for its analysis. ${ }^{2}$

ERL-0510 (Araldite MY0510) is a 4-glycidyloxy-N,N-diglycidylaniline polymer. No signal from ERL-0510 could be detected with the CAU; presumably, this compound is non-volatile, thermally stable, and not amenable to analysis by the CAU.

Thixcin $\mathrm{E}$ is an organic compound that has the form of a white powder. According to the MSDS provided by Rheox, Inc. (Hightstown, N.I), it contains no volatile components. Thus, because the powder could potentially harm the CAU s turbo pump and because the

\footnotetext{
${ }^{2}$ Meltzer, M.; Koester, C.; Ross, S. "Space Shuttle Cleaning Verification: Applications of the Contamination Analysis Unit to Reusable Solid Rocket Motor Production Scenarios", February 1999, Lawrence Livermore National Lab Report Number UCRL-CR-132900.
} 
MSDS indicated that Thixcin ${ }^{\alpha} \mathrm{E}$ contained no volatile compounds that the CAU would be able to detect, it was determined that $\mathrm{Thix}^{\mathrm{a}}{ }^{\mathrm{E}} \mathrm{E}$ was not amenable to analysis by the CAU.

Paraffin is a high molecular weigh hydrocarbon. Because of paraffin s insufficient volatility, no signal from this compound could be detected with the CAU.

\section{Task 2: NBR Insulation Solvent Absorption Tests}

The goal of this task was to determine if the CAU could detect solvent that had soaked into NBR insulation material after an initial drying period. After applying Ionox, PF Degreaser, and Bioact 145 to various NBR surfaces, wiping the surfaces dry, and allowing the surfaces to air-dry for 30 minutes, all of these solvents were easily detected with the CAU.

A second goal was to evaluate the length of time following solvent application during which the CAU could detect residues in the insulation. TCA was detectable for at least 100 hours, and PF Degreaser was detectable for over 300 hours following solvent application. The time course for PF Degreaser on NBR rubber was more complex than that observed for TCA.

\section{Experimental Procedure for Solvent Detection After Initial Drying}

The NBR substrates used in our testing were 0.3 inches thick and mounted on steel plates such that the smooth sides of the rubber were exposed. A rumple cloth was saturated with solvent and used to wipe the surface of the NBR. Immediately after cleaning with solvent, the NBR surface was wiped dry with a rumple cloth. The NBR was allowed to air dry for approximately 15 to 40 minutes before CAU analysis. The CAU, operated in trending mode, was used to detect residual solvent contamination.

The above cleaning procedure deviated from that proposed in the original test plan. The original test plan called for the solvent to puddle and soak the NBR for 30 minutes prior to drying. After cleaning the NBR in this manner, the CAU s filament had not been able to be lit without damage when either the single or double O-ring configuration was used. We believe that the NBR adsorbed a considerable amount of solvent; this solvent desorbed from the NBR in such quantities that, even after the NBR spent approximately 30 minutes under vacuum, the degassing rate remained so high that the CAUs filament would have sustained damage if it had been lit. In addition, it might be possible that the NBR surface swells after solvent cleaning. We observed that, after soaking specific spots on the NBR with solvent, visible, raised areas were present for several days. These spots, with their increased surface areas and increased adsorption sites for water and solvent. might have contributed to the higher operating pressures of the CAU. In any case, to better simulate the manner in which the NBR is typically cleaned, the conditions of the solvent wipe experiments were revised, as described in the previous paragraph.

The solvents tested were Ionox, Bioact 145, and PF Degreaser. Bioact 113, and Bioact PCG, included in the original test plan, were not studied because they contain 
$d$-limonene. Thiokol discovered recently that $d$-limonene damages NBR surfaces. Because Thiokol will no longer use these cleaners, their testing was no longer warranted.

\section{Results}

After approximately half an hour of drying, significant amounts of Ionox and PF Degreaser remained on the NBR. In addition, after drying, traces of Bioact 145 were detected on the NBR. The results of the measurements of Ionox, PF Degreaser, and Bioact 145 are shown in Tables 1, 2, and 3, respectively. In these tables, the absolute signal intensities and integrated peak areas for the specific ions monitored for each solvent are compared against those of an uncontaminated NBR panel. In a previous report, ${ }^{3}$ we considered a solvent to be detected if a) a signal was observed at a value that was ten-fold greater than that of the background (determined by analyzing an uncontaminated NBR panel) and b) detectable signals were observed for at least two solvent ions.

Examination of both the maximum signal intensities of specific ions and their integrated peak areas indicate that Ionox can be detected 45 minutes after the NBR panel has been cleaned and dried; see Table 1. After 45 minutes, the signals produced for many ions remained one hundred times greater than the CAU s background signals for an untreated NBR panel. The signal intensity of the ion of $\mathrm{m} / \mathrm{z} 43$ was especially strong; even after 45 minutes the signal from this ion still saturated the detector. Likewise, integrated peak areas ranged from 10 to 100 fold greater than those of the clean NBR panel.

Table 2 shows that PF Degreaser was still detected on the NBR panel after it had been dried for 40 minutes. While the signals from the lower mass ions of $\mathrm{m} / \mathrm{z} 43$ and $\mathrm{m} / \mathrm{z} 57$ would not meet the previously discussed detection criteria, the signals from the higher mass ions of $\mathrm{m} / \mathrm{z} 71, \mathrm{~m} / \mathrm{z} 85$, and $\mathrm{m} / \mathrm{z} 99$ were easily detectable after 40 minutes. In addition, after 40 minutes, integrated peak areas for all of the studied ions were easily obtained; no integrated peak areas could be obtained for the clean NBR panel. In the case of PF Degreaser, integrated peak areas, and not direct signal intensities, appeared to be the most sensitive indicators of surface contamination.

Integrated peak areas also appeared to be the best indicators of Bioact 145 contamination; see Table 3. Thirty minutes after drying, integrated peak areas for ions monitored to determine contamination of the NBR panel with Bioact 145 could be clearly measured. No integrated peak areas for the same ions were detected on a clean panel. Thus, Bioact 145 can be detected on the NBR.

Signal intensities also indicate that Bioact 145 can be detected on the NBR panel. Signal intensities of ions of $m / 243$ and $m / z 71$ were present at greater than a factor of five times that of the background at both 15 and 30 minutes after drying the NBR. However, if we had used the criterion that the signal intensities for specific ions must be a factor of 10 greater than those of clean NBR to positively detect a solvent, no solvent would have been detected.

\footnotetext{
${ }^{3}$ Meltzer, M.; Koester, C.; Ross, S. "Space Shuttle Cleaning Verification: Applications of the Contanination Analysis Unit to Reusable Solid Rocket Motor Production Scenarios", February 1999, Lawrence Livermore National Lab Report Number UCRL-CR-132900.
} 
The data recorded in Tables 1,2, and 3 were collected up to the point at which the NBR surface reached $100 \mathrm{C}$. The upper temperature boundary for examining NBR was set at $100 \mathrm{C}$ for several reasons. First, as the surface temperature increases, significant amounts of water are desorbed from the NBR surface. Desorbed water contributes to increased operating pressures of the CAU and increases the probability of a filament failure. In addition, NBR that has been heated to $200 \mathrm{C}$ shows a slight brown discoloration, presumably indicating an undesirable surface modification. This discoloration is not apparent at lower operating temperatures. We also suspect that some component of the NBR is outgassing into the CAU, leaving an oily deposit in the sample inlet. This outgassing is expected to be less pronounced at lower operating temperatures.

Both signal intensities and integrated peak areas were useful in determining that Ionox, PF Degreaser, and Bioact 145 could be detected on the NBR surfaces half an hour or more after the NBR surfaces had been cleaned with solvent and wiped dry. In addition, it was observed that the operating vacuum of the CAU was approximately $4 \times 10^{-5}$ torr when clean NBR surfaces were examined. In contrast, a pressure of approximately $6 \mathrm{x}$ $10^{-5}$ torr or greater was observed when analyzing contaminated NBR surfaces. Thus, the operating vacuum of the CAU might also be a useful indicator of surface contamination. This is explored further in the following section.

Table 1. Signals obtained when Ionox was measured on NBR panels. Both maximum signal intensities (in Amps) and integrated peak areas represent data collected up to $100 \mathrm{C}$ (or the highest temperature obtained before the filament turned off). Highlighted cells contain values that meet the criteria for positive signal/integrated area detection (relative to data for clean NBR panel 1 ).

\begin{tabular}{|c|c|c|c|c|c|c|c|c|c|c|}
\hline \multirow[t]{2}{*}{ Ion } & \multicolumn{2}{|c|}{$\begin{array}{c}\text { Clean NBR } \\
\text { panel } 1\end{array}$} & \multicolumn{2}{|c|}{$\begin{array}{c}\text { Clean NBR } \\
\text { panel } 2\end{array}$} & \multicolumn{2}{|c|}{$\begin{array}{c}\text { NBR } \\
\text { (15 min. dry) }\end{array}$} & \multicolumn{2}{|c|}{$\begin{array}{c}\text { NBR } \\
\text { (25 min. dry) }\end{array}$} & \multicolumn{2}{|c|}{$\begin{array}{c}\text { NBR } \\
\text { (45 min. dry) }\end{array}$} \\
\hline & Signal & $\begin{array}{l}\text { Int. } \\
\text { Area }\end{array}$ & Signal & $\begin{array}{l}\text { Int. } \\
\text { Area }\end{array}$ & Signal & $\begin{array}{l}\text { Int. } \\
\text { Area }\end{array}$ & Signal & $\begin{array}{l}\text { Int. } \\
\text { Area }\end{array}$ & Signal & $\begin{array}{l}\text { Int. } \\
\text { Area }\end{array}$ \\
\hline 43 & $9 E-8$ & $3 E-7$ & $1 E-7$ & $3 E-7$ & $>1 \mathrm{E}-6$ & $>1 E-6$ & $>1 E-6$ & $>1 E-6$ & $>1 E-6$ & $>1 \mathrm{E}-6$ \\
\hline 59 & $2 E-9$ & $5 E-8$ & $5 E-9$ & ND & $1 \mathrm{E}-6$ & $1 E-6$ & 1E-6 & $1 E-5$ & $9 \mathrm{E}-7$ & $2 E-5$ \\
\hline 71 & $1 E-8$ & $5 E-8$ & $2 E-8$ & $8 E-9$ & $1 E-6$ & $1 \mathrm{E}-6$ & $7 E-7$ & $1 E-5$ & $4 E-7$ & $9 \mathrm{E}-6$ \\
\hline 72 & $4 E-9$ & $6 E-8$ & $4 E-9$ & $4 \mathrm{E}-8$ & $2 E-7$ & $3 E-7$ & $2 E-7$ & $2 E-6$ & $1 E-7$ & $2 E-6$ \\
\hline 72 & $2 E-9$ & $1 E-8$ & $4 E-9$ & ND & $3 E-7$ & $5 E-7$ & $3 E-7$ & $5 E-6$ & $2 E-7$ & $4 \mathrm{E}-6$ \\
\hline 101 & $5 E-10$ & $5 E-9$ & $7 E-10$ & $6 E-9$ & $2 E-7$ & $3 E-7$ & $2 E-7$ & $2 E-6$ & $1 E-7$ & $3 E-6$ \\
\hline
\end{tabular}

ND indicates that a signal was not detected. 
Table 2. Signals obtained when PF Degreaser was measured on NBR panels.

Both maximum signal intensities (in Amps) and integrated peak areas represent data collected up to $100 \mathrm{C}$ (or the highest temperature obtained before the filament turned off). Highlighted cells contain values that meet the criteria for positive signal/integrated area detection.

\begin{tabular}{|c|c|c|c|c|c|c|}
\hline \multirow{2}{*}{ Ion } & \multicolumn{2}{|c|}{$\begin{array}{c}\text { Clean NBR } \\
\text { panel }\end{array}$} & \multicolumn{2}{c|}{$\begin{array}{c}\text { NBR } \\
(20 \text { min. dry })\end{array}$} & \multicolumn{2}{c|}{$\begin{array}{c}\text { NBR } \\
\text { (40 min. dry) }\end{array}$} \\
\hline & Signal & $\begin{array}{c}\text { Int. } \\
\text { Area }\end{array}$ & Signal & $\begin{array}{c}\text { Int. } \\
\text { Area }\end{array}$ & Signal & $\begin{array}{c}\text { Int. } \\
\text { Area }\end{array}$ \\
\hline 43 & $7 E-8$ & ND & $7 E-7$ & $2 E-5$ & $5 E-7$ & $9 E-6$ \\
\hline 57 & $5 E-8$ & ND & $6 E-7$ & $1 E-5$ & $4 E-7$ & $6 E-6$ \\
\hline 71 & $2 E-8$ & ND & $2 E-7$ & $5 E-6$ & $2 E-7$ & $3 E-6$ \\
\hline 95 & $7 E-9$ & ND & $1 E-7$ & $3 E-6$ & $9 E-8$ & $2 E-6$ \\
\hline 99 & $2 E-9$ & ND & $2 E-8$ & $5 E-7$ & $2 E-8$ & $2 E-7$ \\
\hline
\end{tabular}

ND indicates that a signal was not detected.

Table 3. Signals obtained when Bioact 145 was measured on NBR panels. Both maximum signal intensities (in Amps) and integrated peak areas represent data collected up to $100 \mathrm{C}$ (or the highest temperature obtained before the filament turned off). Highlighted cells contain values that meet the criteria for positive signal/integrated area detection.

\begin{tabular}{|c|l|l|l|l|l|l|}
\hline Ion & \multicolumn{2}{|c|}{ Clean NBR panel } & \multicolumn{2}{c|}{$\begin{array}{c}\text { NBR } \\
\text { (15in. dry) }\end{array}$} & \multicolumn{2}{c|}{$\begin{array}{c}\text { NBR } \\
\text { (30 min. dry) }\end{array}$} \\
\hline & Signal & $\begin{array}{c}\text { Int. } \\
\text { Area }\end{array}$ & Signal & $\begin{array}{c}\text { Int. } \\
\text { Area }\end{array}$ & Signal & $\begin{array}{c}\text { Int. } \\
\text { Area }\end{array}$ \\
\hline $\mathbf{4 3}$ & $1 \mathrm{E}-7$ & ND & $6 \mathrm{E}-7$ & $4 \mathrm{E}-6$ & $5 \mathrm{E}-7$ & $5 \mathrm{E}-7$ \\
\hline $\mathbf{5 7}$ & $7 \mathrm{E}-8$ & ND & $3 \mathrm{E}-7$ & $2 \mathrm{E}-6$ & $2 \mathrm{E}-7$ & $8 \mathrm{E}-8$ \\
\hline $\mathbf{6 9}$ & $5 \mathrm{E}-8$ & ND & $1 \mathrm{E}-7$ & $6 \mathrm{E}-7$ & $1 \mathrm{E}-7$ & $5 \mathrm{E}-8$ \\
\hline $\mathbf{7 1}$ & $2 \mathrm{E}-8$ & ND & $1 \mathrm{E}-7$ & $5 \mathrm{E}-7$ & $1 \mathrm{E}-7$ & $6 \mathrm{E}-9$ \\
\hline $\mathbf{8 3}$ & $3 \mathrm{E}-8$ & ND & $7 \mathrm{E}-8$ & $2 \mathrm{E}-7$ & $6 \mathrm{E}-8$ & $5 \mathrm{E}-8$ \\
\hline $\mathbf{8 5}$ & $1 \mathrm{E}-8$ & ND & $4 \mathrm{E}-8$ & $1 \mathrm{E}-7$ & $3 \mathrm{E}-8$ & $3 \mathrm{E}-8$ \\
\hline $\mathbf{9 5}$ & $2 \mathrm{E}-8$ & ND & $5 \mathrm{E}-8$ & $1 \mathrm{E}-7$ & $5 \mathrm{E}-8$ & $3 \mathrm{E}-8$ \\
\hline $\mathbf{9 7}$ & $2 \mathrm{E}-8$ & ND & $4 \mathrm{E}-8$ & $1 \mathrm{E}-7$ & $4 \mathrm{E}-8$ & $3 \mathrm{E}-8$ \\
\hline $\mathbf{1 1 1}$ & $9 \mathrm{E}-9$ & ND & $2 \mathrm{E}-8$ & $1 \mathrm{E}-7$ & $2 \mathrm{E}-8$ & ND \\
\hline 126 & $2 \mathrm{E}-9$ & ND & $2 \mathrm{E}-8$ & $1 \mathrm{E}-8$ & $5 \mathrm{E}-9$ & $2 \mathrm{E}-9$ \\
\hline
\end{tabular}

ND indicates that a signal was not detected.

\section{Experimental Procedure for Prolonged Solvent Detection}

We evaluated two solvent cleaners for NBR rubber, for possible detection for prolonged periods following application. We collected mass spectra for PF Degreaser (PFD) to identify candidate ions, and used mass peaks found in NIST mass spectral libraries for a comparison solvent, trichloroethane (TCA). As before, we used a multiple-ion monitoring mode to collect thermal desorption trend curves from panel washed with the two solvents, with time following solvent application, to assess the period during which the CAU might provide indication of residual solvent in the rubber that might compromise further bonding procedures. We also monitored outgassing by measurement of total system pressure during thermal desorption. This latter data appeared sufficiently 
useful that we also include a lower-cost design for a modified CAU that uses pressure monitoring exclusively to detect solvents in insulation materials.

Prior to collecting data, we performed desorption runs (heating cycles starting at $\sim 25-30$ $\mathrm{C}$, ending at $\sim 120 \mathrm{C}$ ), monitoring residual ions for water and TCA (masses 18, 61, 63, 97, 99,117 and 119) to verify the integral value (integrated area above a hand-selected pair of baseline points) was less than $1 \times 10 .^{-10}$ The ion current integral is further discussed below.

Two inch square test panels were cut from the $6 \times 6$ NBR coated steel panels supplied by Thiokol, using a bench shear. We noted there were two finishes of the NBR in the batch supplied for testing, one with a glossy-smooth surface (for about 1/3 of the panels), and a second rough-textured finish. We elected to focus on the latter, as a worst-case scenario for sealing to the CAU sampling nose.

Ions used for monitoring TCA residues were those listed above, found in a NIST mass spectral library. Selection of candidate ions for PFD was performed by slowly desorping an NBR test panel, with temperature rising at $0.5 \mathrm{C} / \mathrm{sec}$, while using the CAU spectrum scan mode. Figure 1 shows the mass spectra obtained for this material and a blank NBR panel. Note that the heating rates used for thermal desorption of NBR was half the rate used in experiments with materials directly applied to stainless steel test panels (see procedures in Task 5). When the higher heating rate $(1 \mathrm{C} / \mathrm{sec})$ was used, outgassing of the NBR alone was sufficiently rapid that the RGA control software generated a fault condition resulting in filament shutdown and premature termination of the measurement. Lowering both the heating rate and the target ramp temperature $(120 \mathrm{C}$ as opposed to 250 $\mathrm{C}$, used as the target with stainless steel test coupons) permitted routine assays, with only a modest increase in the total time for each measurement.
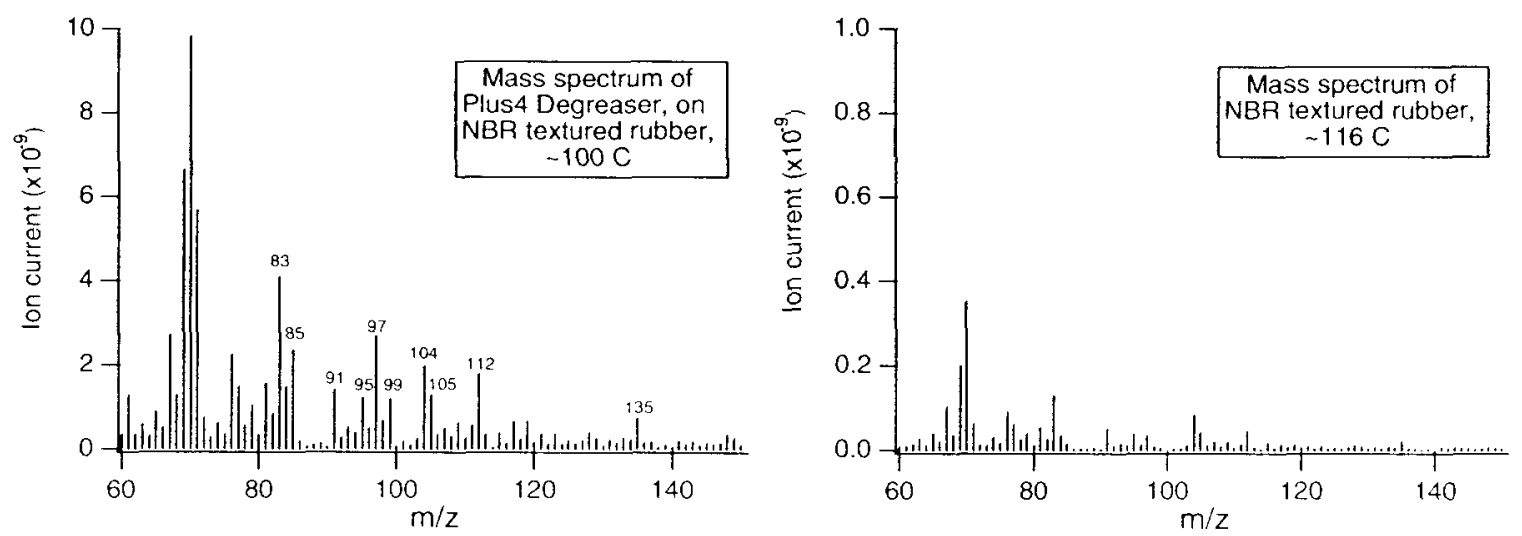

Figure 1. Mass spectnum of PF Degreaser (PFD) applied to a panel of NBR rubber during thermal desorption (left), and a mass spectrum of an untreated NBR panel (right). Note that the CAU response to the untreated pancl in this case was less than a tenth of the response to the solvent washed pancl. Ions selected for routine monitoring of PFD residues are labeled in the figure at left.

The solvents were applied using a technique designed to approximate a washing procedure. A fresh $5 \times 8$ lab wipe was folded into a $1 \times 1.5$ pad and clamped with a hemostat. To achieve a uniform degree of saturation, solvents were applied to an upper corner while the pad was held at an angle, until solvent just dripped from the pad. The test panels were cleaned with the solvent saturated pads for 30 seconds. In the case of 
TCA applications, the solvent evaporated from the rubber surfaces so quickly that no wiping of residual solvent was needed. However, PFD left the surfaces noticeably wetted, and were dried with a second lab wipe. Fresh wipes were used for each panel to avoid cross contamination or buildup of extracted materials on the wipes. The panels were allowed to stand in open air for at least 10 minutes, and then kept in plastic Petri dishes to avoid dust deposits prior to measurements. Measurements were performed at intervals ranging from around six hours to over 300 hours following solvent application.

In order to evaluate possible drift in instrument response, and to better assess the precision of the CAU measurements on NBR, a pair of measurements was made at each time interval following solvent application, and a pair of untreated NBR panels were measured (with the ions of the respective target compounds) as blanks at each subsequent measurement session.

\section{Results: Detection of TCA}

Plots of CAU system pressure and ion current integrals for panels washed with TCA are shown in Appendix A, Figures A-1 and A-2. In all plots, solid symbols and lines are treated panels, open symbols and dotted lines are untreated blank NBR panels. Lines connect the means of two measurements.

With the exception of the plots of the water peak (ion 18), total system pressure and the other ions measured produced similar plots, with an initial rise in response following the first measurement, to a peak at approximately 20 hours, followed by a rapid decline to levels near the untreated blanks at around 100 hours after treatment. As described in the discussion of signal integration methods (Task 5), integration of ion current against time during sample heating gave a larger apparent signal than integration of ion current against sample temperature.

We also note that the total system pressure (measured with the CAU RGA) also easily distinguishes the treated from untreated panels during the first 100 hours following treatment. This will be discussed below in the context of a lower-cost approach to detection of cleaners on NBR rubber surfaces.

\section{Detection of PF Degreaser}

Data for thermal desorption of PF Degreaser treated NBR panels are shown in Appendix A, Figures 3 through 5. The result for three of the ion measurements (AMUs 85, 97, and 135) generally resemble the results from TCA applications, with an early rise in response followed by a decline to responses close to untreated blanks at around 100 hours after treatment. However, other distinct responses were also obtained. For system pressure and several ions (e.g.: AMUs 91, 95, 99, 104, and 105) we observed a bimodal trend, with a second rise in response starting around 150 hours after solvent application, and reaching a second broad maximum around 260 hours after the initial washing. Notably, in the case of AMU 99, washed panels gave readings well above the untreated controls for the entire duration of the experiment. Finally, for ions at AMU 83 and 112, washed panels generated lower ion current integrals at several time intervals following solvent application, even just after solvent application; for these ions the overall signal levels 
were low, and precision was lower than for other candidate ions. These two ions are unlikely choices for PFD monitoring on NBR substrates.

\section{Alternative Lower-Cost Instrument Configuration}

The plots of total system pressure shown in Appendix A, Figures 1 and 3 suggest that monitoring the solvent outgassing profile during thermal desorption offers a route to a potentially lower-cost instrument configuration that could also improve system ruggedness and ease of field use. In Figure 2 cartoons of the present RGA-based CAU and an alternative design that would monitor solvent residues with a self-contained highvacuum gauge instead of the more expensive quadrupole RGA. This Flex design would reduce the number of cases that support the system to one, possibly cart mounted case that would hold the roughing and turbo pumps, heater power supplies and controllers, and a high-vacuum manifold similar to the one now used to shroud the RGA pole magnets, and support the turbo pump. Instead of mounting this manifold directly onto the substrate to be measured, the sampling nose of the instrument would be mounted on the end of a flexible, large bore high vacuum capable line (stainless bellows, etc.), that could be thermostatted, if necessary. Vent lines, thermocouple and heating lines could be bundled with the large-bore line to simplify cable and hose handling. This design also would allow the operator to position the vacuum system case and easily interrogate multiple

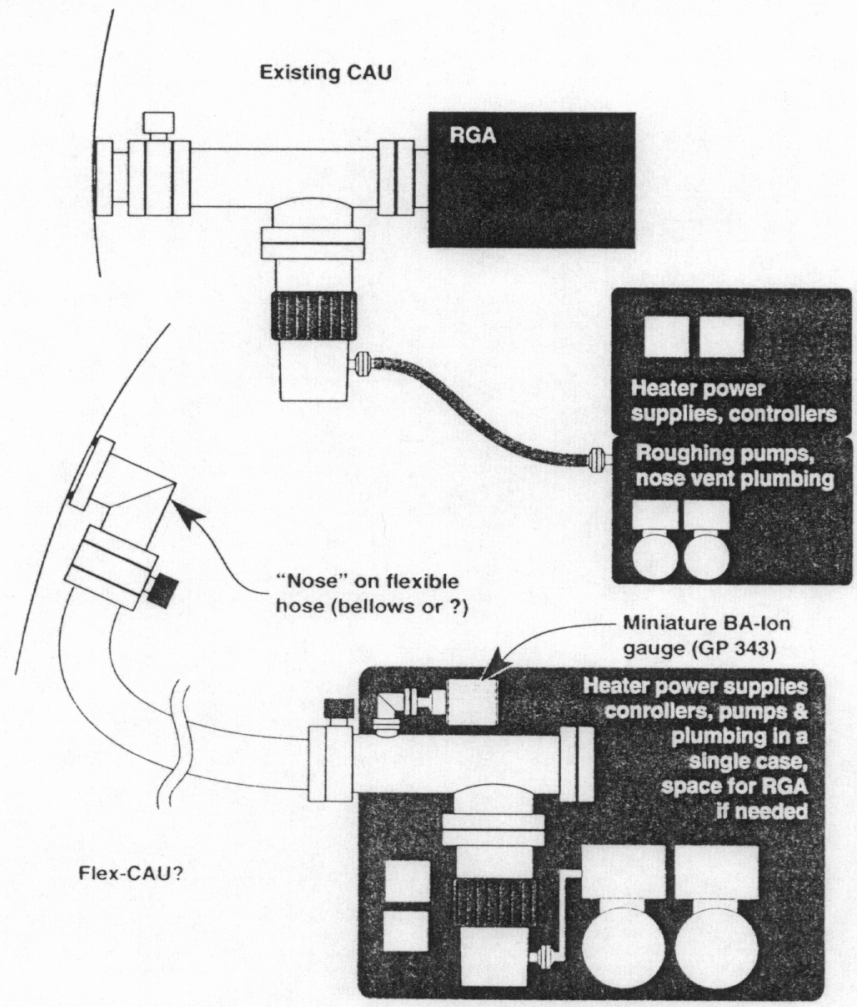

Figure 2. Schematic diagrams of the present RGA-based CAU (above). and an alternative, lower cost and higher portability unit based on measurements of total solvent outgassing. 
points with the sampling nose prior to moving to a new location. We suggest this would facilitate collection of more data points, and ease sampling when compared with the present $\mathrm{CAU}$, in which the nose, high vacuum manifold, turbo pump and RGA form a rigid package.

Careful attention to design of component positioning in the case could allow temporary addition of an RGA, if the additional mass-specific information was needed. This situation could be envisioned if new solvents were introduced for testing, or if other new or unusual circumstances were encountered, yet the system could be easily reconfigured to the default (pressure-only) setup, relying on lower cost, self contained vacuum gauges for routine operation. This could leverage the investment of a single RGA across numerous pressure-only field monitoring units. To get some idea of the cost reduction, field-hardened vacuum measurement systems with a measuring range from atmospheric pressure to $5 \times 10^{-8}$ Torr (with, e.g.: a mini-Convectron ${ }^{\circ}$ and Mini-Ion ${ }^{\circ}$ gauge combination, Granville-Phillips, Inc.) are now available for as little as $\$ 1300$.

\section{Task 3: Curved Surface Analysis}

The objective of this task was to determine if the CAU could analyze surfaces of 5-foot (diameter) and 12-foot (diameter) curvatures. The test was considered successful if sufficient vacuum was obtained to operate the CAU when its single O-ring inlet was placed on the curved surface.

\section{Experimental Procedure}

Curved plates of stainless steel, having diameters of 5 feet and 12 feet, were obtained from Thiokol. The stainless steel pieces had a surface roughness of approximately 63-123 microinches, as determined using an S-22 Microfinish Comparator (Gal Electroforming Division, Danbury, CT). Both the inner and outer surfaces of the curve were held to the single O-ring inlet of the CAU. Two people were required to achieve proper placement of the CAU on the plate -- one person was required to position the plate and a second person was needed to control the CAU s vacuum valves.

\section{Results}

Sufficient vacuum was achieved to allow analyses of both inner and outer surfaces of the $5 \mathrm{ft}$ and the $12 \mathrm{ft}$ diameter plates. For this reason, it was not necessary to custom-build new. curved sample inlets, as we originally anticipated. Thus, the CAU, as currently configured, is capable of analyzing inner and outer surfaces of both the RSRM and the nozzle throat housing. 


\section{Task 4: Solvent Extraction and Gas Chromatography Analysis}

\section{Head Space Analysis of Rubber Insulation Cores}

We evaluated the utility of performing head space analyses of cores taken from NBR and EPDM rubber samples to which contaminants had been applied, in order to determine penetration and outgassing characteristics versus time. In studying previous work performed by Thiokol $^{4}$, we determined that this area of investigation had already been covered, and not enough new information would be generated to warrant the study we d envisioned.

\section{Gas Chromatography Analysis}

Gas chromatography is a prominent technique for separating complex gases and analyzing the relative quantities of the individual components. A high sensitivity gas chromatograph (GC) developed at LLNL was employed to determine whether GC approaches are able to enhance the surface analysis data available through use of the mass-spectrometer-based CAU. An investigation of GC capabilities was performed at LLNL using a hand-held, real-time detection GC that employed our Micro-ElectroMechanical-System (MEMS) technology. The total weight of the MEMS GC is approximately 8 pounds, and it measures 8 inches by 5 inches by 3 inches. It consumes approximately 12 watts of electrical power and has a response time on the order of 2 minutes. Light volatiles can be analyzed in under 30 seconds. Special microetching techniques typically employed to fabricate channels in silicon wafers were used to fabricate the MEMS GC s 6 meter, spiral separation column. The existing LLNL/MEMS GC employs a helium plasma detector, that essentially mimics the sensitivity and selectivity of an FID. The column temperature of the GC can range as high as $350 \mathrm{C}$.

The MEMS GC shows promise for being an excellent, easily transportable tool for organic chemical analyses. So far, however, the MEMS GC has only been applied to analyses of gases. We tested the MEMS GC by sampling air that had passed over panels with small amounts of HD-2 grease. Peaks were detected at grease concentrations comparable to those used for characterization of the CAU, but reproducibility was modest, and some sample loss may have occurred in the unheated inlet of the unit. The preliminary analysis conducted for the present project showed that the MEMS GC has potential as a surface analysis tool, but further development would be required for this application.

\footnotetext{
'L.L. Biegert, Use of GC/MS and Microtome Techniques as Methods to Evaluate ODC Free Cleaner Diffusion and Evaporation in Insulation and Phenolic Case Material. Thiokol Propulsion. 2000).
} 


\section{Task 5: Detection Limit Studies}

A major part of the project consisted of detection limit determinations for residual materials of interest in Reusable Solid Rocket Motor (RSRM) operations. Analyses or attempted analyses were conducted of the following materials:

ChemLok 205
ChemLok 233
TIGA 321, Part A
TIGA 321, Part B

Polysulfide PR-1422, Part A

Polysulfide PR-1422, Part B

Silicone DC 90-006-02 Base

Silicone DC 90-006-02 Catalyst

We also discuss an evaluation of our integration techniques for analyzing contaminant data, and an improvement in our integration approach, compared to methods used in previous work.

\section{Experimental Setup}

We applied measured amounts of materials that were soluble or suspendable in common solvents onto stainless steel panels. Then we determined whether the CAU could detect the materials. We varied concentrations of the materials from less than 1 to over 30 $\mathrm{g} / \mathrm{cm}^{2}$

The first step in the evaluation of the materials that were the focus of this study involved a slow desorption run, with temperature rising at a rate of $1 \mathrm{C} / \mathrm{sec}$, on a spot with a high concentration of contaminant. This step was performed using the CAU spectrum scan mode. In this mode, we examined mass spectra from AMU 50 to 200 in order to identify ions that were characteristic for each soil. Figure 3 shows the mass spectra obtained for the subject materials (as well as for HD-2 grease) during spectrum scan runs.

Characteristic ions for each material were then evaluated in more detail using the CAU s selected ion monitoring mode, with temperature ramping from 40 to $250 \mathrm{C}$ at $1 \mathrm{C} / \mathrm{sec}$.

\section{Instrument Response Determination}

To determine instrument response, we deposited a known amount of soil on a stainless steel test panel and analyzed that panel. To accomplish this, a measured quantity of the soil was added to a solvent, and a measured amount of this was applied to the test panel. Some of the soils did not dissolve in the solvent, but did form fine suspensions, from which solids would settle if allowed to stand; these were shaken to thoroughly suspend particulates prior to spotting on the steel test panels. The solvent was allowed to evaporate, leaving a small, but known, quantity of soil on the test panel.

In earlier work, standard solutions used to determine detection limits of HD-2 calcium grease and other materials were prepared in methylene chloride. We evaluated the solubility of the remaining soils in this solvent. The materials supplied for testing in the present experiments are listed in the Table 4, with some comments on their bulk properties and solubility characteristics. In this table, a + indicates that the soil was soluble or suspendable in methylene chloride, or in other words, that the soil either 
dissolved or formed a stable suspension or emulsion that was acceptable to work with for instrument response and detection limit studies. The symbol - indicates that the material was not soluble or suspendable. Of the solvents tested, ChemLok 233 and Polysulfide PR1422A did not dissolve or form a suspension in methylene chloride.
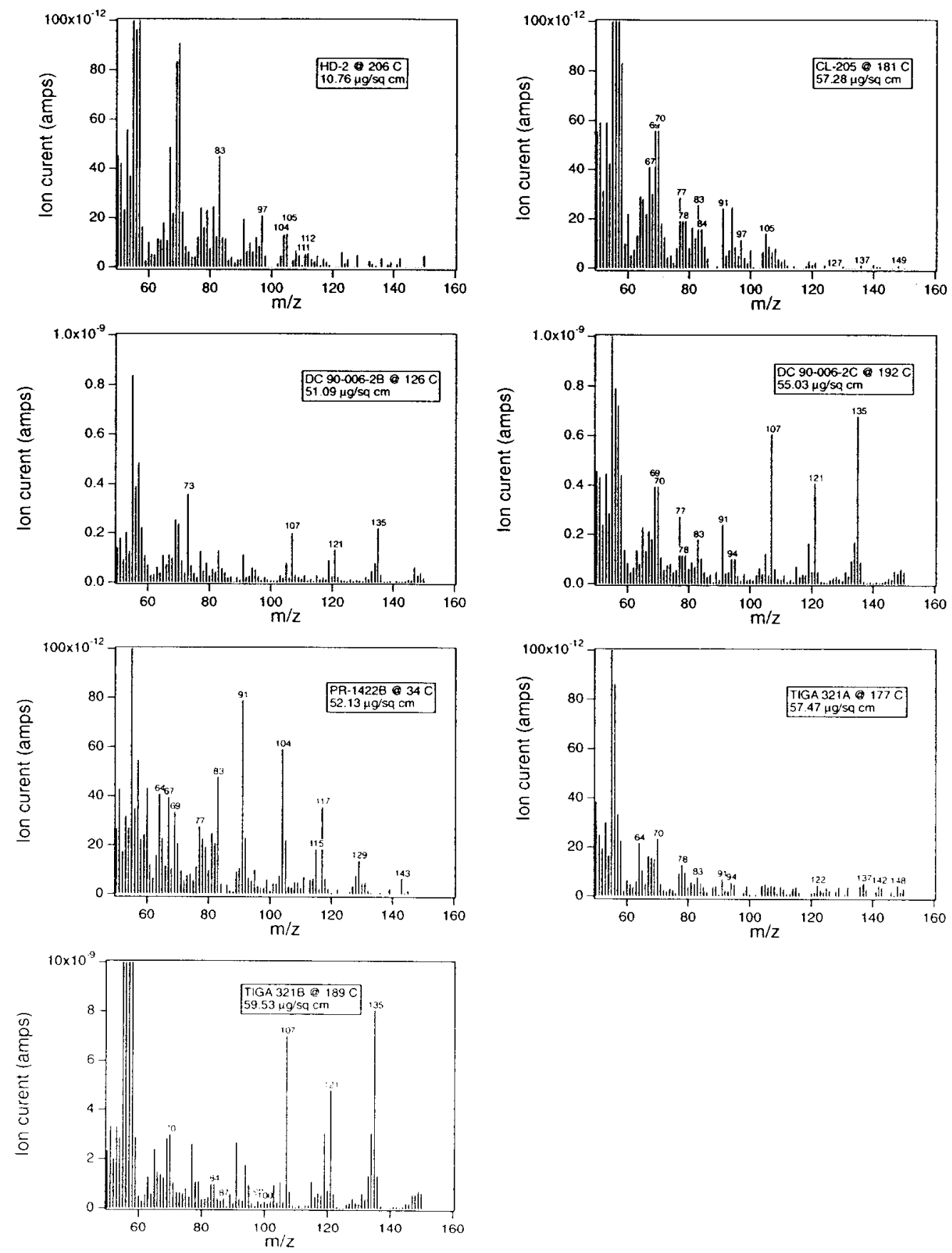

Figure 3. Mass spectra of various materials collected with the Contamination Analysis Unit (CAU).

Characteristic ions used for selected ion monitoring thermal desorption experiments are labeled with their $m$. values. Note that large differences in vapor pressure or boiling point of the various materials give rise to differences in sensitivity. 
Table 4. Gross properties of sealants, coatings, and other materials tested.

\begin{tabular}{|c|c|c|c|}
\hline Material name & Abbreviation & Appearance & $\begin{array}{c}\text { Solubility in } \\
\mathrm{CH}_{2} \mathrm{Cl}_{2}\end{array}$ \\
\hline ChemLok 205 & CL 205 & $\begin{array}{c}\text { Grey liquid, settled } \\
\text { solids; strong solvent } \\
\text { odor }\end{array}$ & $\begin{array}{c}+ \\
\left(\text { solids }^{*}\right)\end{array}$ \\
\hline ChemLok 233 & $\mathrm{CL} 233$ & Black solid; hard & - \\
\hline TIGA 321 ,Part A & TIGA-A & $\begin{array}{l}\text { Moist/soft putty w/vs. } \\
\text { mild odor }\end{array}$ & $\begin{array}{l}+ \\
\text { (fibrous } \\
\text { solids) }\end{array}$ \\
\hline TIGA 321 ,Part B & TIGA-B & $\begin{array}{l}\text { Moist/soft putty } \\
\text { w/strong ammonia } \\
\text { odor }\end{array}$ & + \\
\hline Polysulfide PR-1422, Part A & PR-1422A & $\begin{array}{l}\text { Moist/soft; mild rubber } \\
\text { odor }\end{array}$ & - \\
\hline Polysulfide PR-1422, Part B & PR-1422B & $\begin{array}{c}\text { Stiff paste; faint } \\
\text { solvent odor }\end{array}$ & + \\
\hline Silicone DC 90-006-02 Base & DC 90-006-02B & $\begin{array}{c}\text { Moist/soft; faint rubber } \\
\text { odor }\end{array}$ & $\begin{array}{c}+ \\
\text { (solids) }\end{array}$ \\
\hline Silicone DC 90-006-02 Catalyst & DC $90-006-02 C$ & $\begin{array}{c}\text { Clear liquid w/brown } \\
\text { settled solids }\end{array}$ & $\begin{array}{c}+ \\
\text { (solids) }\end{array}$ \\
\hline
\end{tabular}

*solids indicates fine particles or fibers settle out within minutes to hours of initial mixing.

ChemLok 233 and Polysulfide PR1422A were also tested for solubility in hexane, acetone and isopropanol, and were insoluble or not suspendable in those solvents. Therefore, at the current time, we are unable to determine instrument response for these solids. If a suitable suspension solvent can be found for these materials, we will return attention to them.

The remaining materials were dissolved or suspended in methylene chloride, stored in 2 $\mathrm{ml}$ septum-capped vials, and refrigerated until needed. The samples were applied to a 1 $\mathrm{cm}$ diameter recessed well on stainless steel sample plates, then analyzed by the CAU. The CAU nose encloses an $8 \mathrm{~cm}^{2}$ area on the sample plates. In order to approximate average concentration per unit area under the CAU nose, the actual amounts of each material applied to the stainless steel sample plates were divided by 8 . These average concentrations are referred to as area-corrected concentrations. The area-corrected concentrations ranged from less than $1 \mathrm{~g} / \mathrm{cm}^{2}$ to over $30 \mathrm{~g} / \mathrm{cm}^{2}$

To perform a measurement, the sample panel was placed on the nose of the instrument with the sample chamber gate valve closed; the nose was then evacuated with a roughing pump, and the gate valve opened to the high vacuum of the CAU detector. System pressure was monitored for $\sim 30$ seconds to assure stability, after which heating was started. Ion currents remain relatively constant until after heating of the sample nose commences. As can be seen in Figure 4, rises in ion current typically occur in combinations of sharp early peaks and broader later peaks, possibly caused by different compounds being emitted as the steel sample panel temperature rises. 

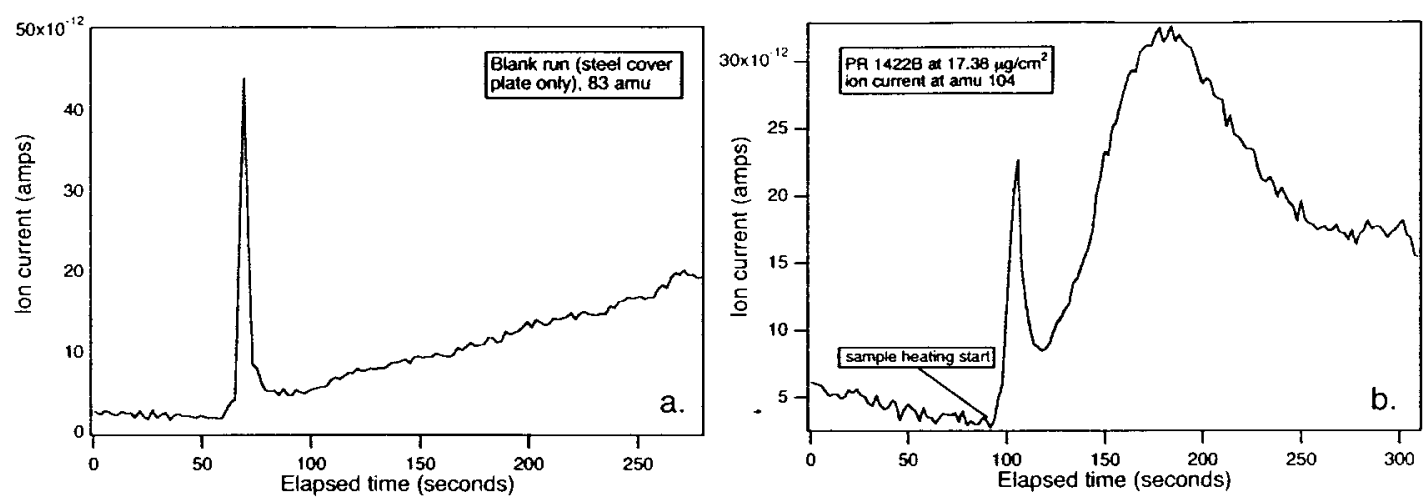

Figure 4. Ion current thermograms recorded with the CAU. Figure a.: Typical blank run with clean stainless steel sample panel. Figure b.: Typical thermogram (ion current response vs. time plots) of tested soils.

\section{Modified Integration Procedure}

Past work has shown that maximum CAU sensitivity can be attained if signals are quantified by integrating the areas under ion current peaks. One of the objectives of the present work was to evaluate and improve upon our integration approach. We examined three methods for signal integration: ion current against time, both including and excluding the sharp early peaks observed just after the start of heating, and integration of ion current against sample temperature. When plotting ion current against temperature, the early peaks were sufficiently compressed as to make their starting point difficult to identify. For this reason early peaks were excluded from the ion current/temperature integrations (Figure 5).
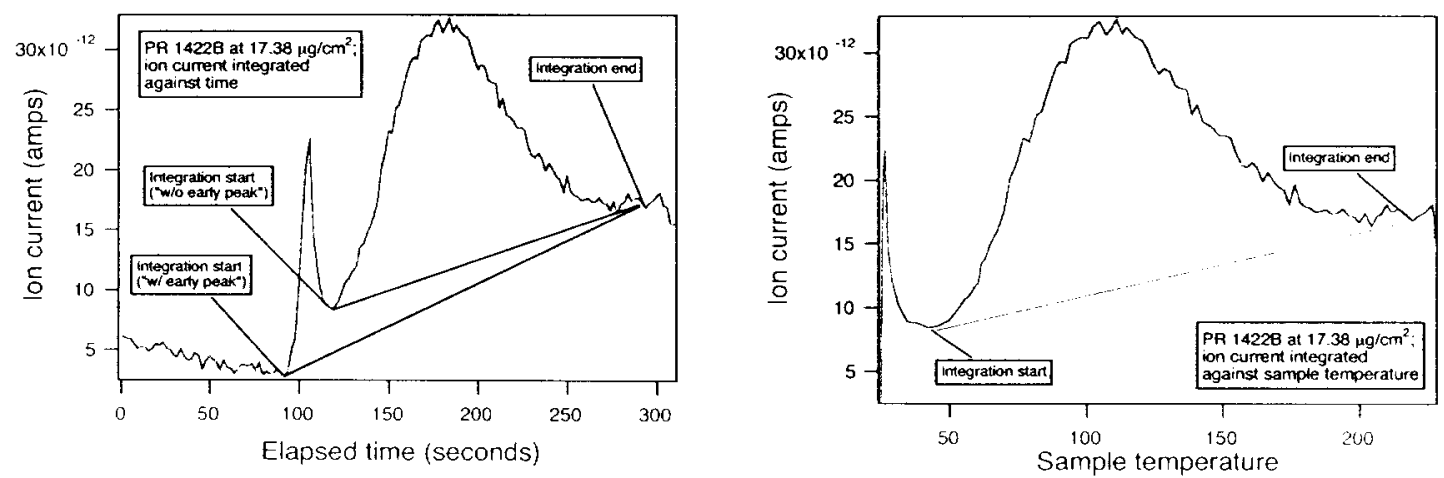

Figure 5 . Ion current integration against tine, with and without inclusion of early peaks (keft), and integration aganst sample temperature (right).

There are various definitions of detection limits (DLs) used to describe the sensitivity of analytical instruments. The detection limit definition that we have used with CAU data is the minimum amount of material that produces an ion current integral value of at least $1 \times 10^{-9}$ (for an ion current vs. sample temperature integration, excluding early peaks), for at least two characteristic ions for a given material. In addition, we required that we be able to see this amount of material on 3 different days. We have since found indications that a greater CAU sensitivity can often be attained through integrations of ion current 
against time (rather than sample temperature), including integration of the early peaks. We have thus modified our method for determining detection limits by implementing this new signal integration procedure. Plots illustrating the results obtained from the different integration methods are shown in Appendix A.

\section{Individual Ion Detection Limit Results}

Table 5 lists the concentrations of sample materials that generated ion current integrations above $1 \times 10,^{-9}$ for each of the candidate ions monitored. During initial experiments, DC 09-006-02C and CL-205 were not detected for any of the monitored ions selected from full spectrum scans, at the highest concentrations applied $\left(37\right.$ and $38 \mathrm{~g} / \mathrm{cm}^{2}$, respectively), and are omitted from this table. The CAU was able to easily detect TIGA$321 \mathrm{~B}$ and PR1422B at concentrations below $10 \mathrm{~g} / \mathrm{cm},{ }^{2}$ and TIGA-321B at levels near $20 \mathrm{~g} / \mathrm{cm} .^{2}$ DC-90-006-02B was poorly detected, with good sensitivity for only one ion. In keeping with the approach described earlier for reporting detection limits (least amount detected for two ions, on three separate days), the detection limits for these soils are: DC 90-006-02B, $30 \mathrm{~g} / \mathrm{cm}^{2}$; TIGA-321B, $2 \mathrm{~g} / \mathrm{cm}^{2}$; TIGA-321A, $17 \mathrm{~g} / \mathrm{cm}^{2}$; and PR1422B, $8 \mathrm{~g} / \mathrm{cm}^{2}$.

Table 5. Detection limits for individual candidate ions of various surface contaminants, in units of $\mathrm{g} / \mathrm{cm}^{2}$. Values are area corrected concentrations that yielded ion current integrals above $1 \times 10,9$ for ion current vs. time integrations (including early peaks; means of three measurements, run on separate days).

\begin{tabular}{|c|c|c|c|c|c|c|c|c|c|c|c|c|c|c|}
\hline \multirow[b]{2}{*}{ Material } & \multicolumn{14}{|c|}{ AMU } \\
\hline & 64 & 69 & 70 & 73 & 83 & 84 & 87 & 91 & 98 & 100 & 107 & 121 & 122 & 135 \\
\hline DC 90-006-02B & & & & 10 & & & & & & & 30 & 30 & & 30 \\
\hline TIGA-321B & & & 1 & & & 2 & 2 & & 2 & 3 & 2 & 2 & & 2 \\
\hline TIGA-321A & & & 16 & & 22 & & & 17 & & & & & 20 & \\
\hline PR1422B & 5 & 7 & & & & & & 8 & & & & & & \\
\hline
\end{tabular}

\section{Discussion of Signal Integration Methods}

The different materials examined exhibited different characteristic peak shapes during thermal desorption (Figure 6), ranging from single, well-defined peaks (Figure 6a), to combinations of early, sharp peaks with later, well-defined broad peaks (Figure 6b), to runs with sharp early peaks and poorly defined later peaks (Figures 6c, 6d). Since early peaks were observed on some blanks (Figure 4) as well as on many samples, the possibility existed that these peaks were a background contribution to the measurement. and not actual ion current from the contaminant sample. This prompted comparison of ion current integrations that excluded and included the early signals. The graphs in Appendix A depict data from three methods of ion current integration for selected ions of various contaminants, over a range of different concentrations.

For several sample runs (for instance, Appendix B, Figures B-1 and B-3), integrations with and without the early peaks were virtually identical, which suggests little contribution to ion current from the early peak. In other cases (Figure B-2, a through $f$, 
and Figure B-9, a through d), easily visible contributions were made by adding the early peaks. In these cases, the early peaks may represent a fraction of the sample that is easily dislodged soon after heating commences, leaving behind a residue that desorbs more slowly as the temperatures rise. The results in the appendix suggest that additional CAU sensitivity may be attained in some cases by including early peaks in the ion current integration.

The possible contribution of the instrument itself to these early peaks will be examined further in future work. Blank, cleaned sample plates, as well as contaminated plates, can exhibit early peaks, as seen in Figure 4. In this work, although blanks were run daily, they were run with the ions used to detect HD-2 grease. Preferably, the ions used to examine new candidate materials could be used. We will also examine the effect of maintaining the CAU sampling nose at baking temperatures between sessions; in the present work the CAU was kept evacuated, but we discovered that the I/O board presently used to control desorption temperature does not reliably hold its analog output for prolonged periods. This will need to be addressed in future implementations.
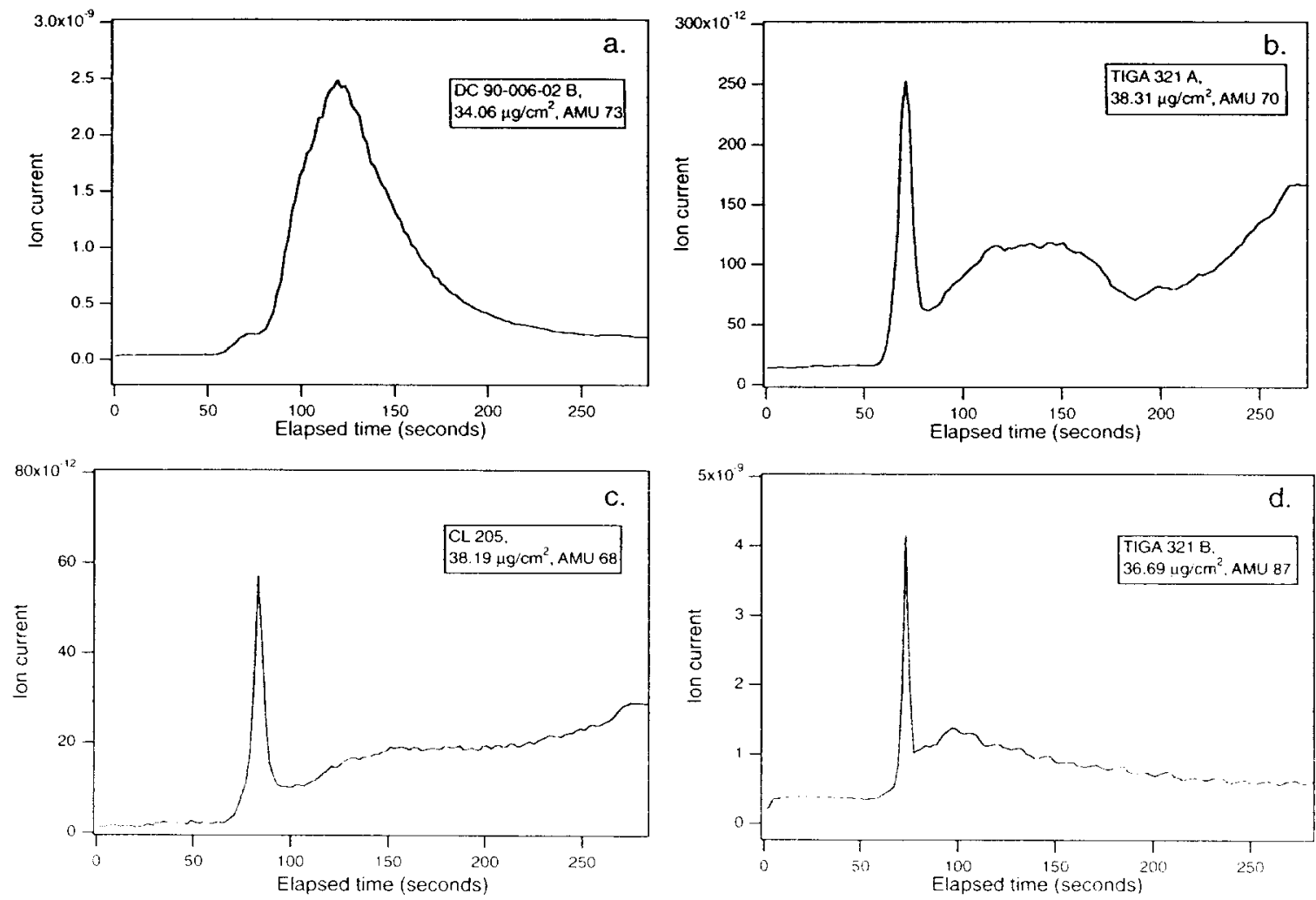

Figure 6. Variation in thermal desorption peak shapes observed from the candidate materiats.

\section{Softuare Modifications}

Several minor modifications were made to the analysis program used to process the experimental data (Figure 7). First, we discovered that the existing analysis program lacked the ability to open selected ion monitoring mode data on disk. These files are stored by the CAU control software in ASCII text, while spectrum scan mode data are 
stored as binary files. In addition to adding the capability of reading the selected ion monitoring files, an indicator was added to help visualize the magnitude of the ion current integral, so as to reduce the subjectivity involved in setting the integration endpoints.

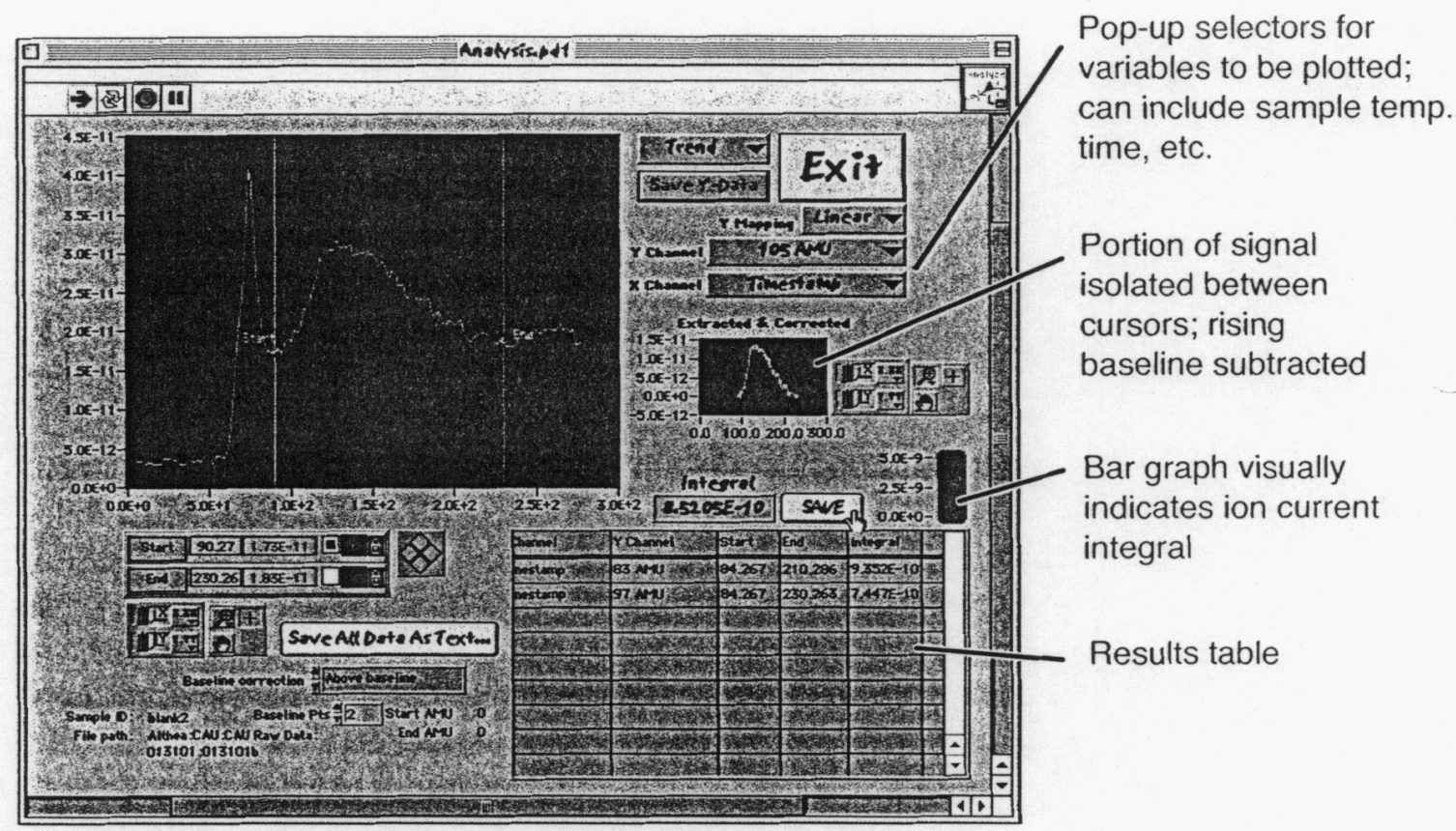

Figure 7. User interface panel for data analysis, showing an integration of ion current against elapsed time.

\section{Conclusions}

Detection limits ranged from $1-30 \mathrm{~g} / \mathrm{cm}^{2}$ for the compounds examined, with the exception of ChemLok 205, Silicone DC 90-006-02 Catalyst, and the two materials that could not be dissolved or suspended in solvents (Chemlok 233 and Polysulfide PR$1422 \mathrm{~A})$. The results presented characterize the CAU s sensitivity for detecting trace amounts of a range of different surface residues.

\section{Task 6: Black Light Testing}

\section{Testing for O-ring Residues Using Black Light Inspection}

O-rings made of Viton, general purpose silicone, and high temperature silicone were used in the CAU, and contacted clean stainless steel plates at typical vacuum levels and at temperatures of $250 \mathrm{C}$ for the Viton O-ring, and $300 \mathrm{C}$ for the silicone O-rings. No detectable residues, as determined with ultraviolet irradiation ( black light ), were evident on stainless steel plates that had the O-rings during routine operation of the CAU. However, clean O-rings made from these materials did not themselves fluoresce when exposed to black light. Thus, black light testing does not appear to be an appropriate approach for determining residues from contact with these O-ring materials. 
Relative Sensitivities of Black Light Inspection vs. CAU Analysis

HD-2 Grease: HD-2 grease was applied to stainless steel plates in the usual manner. Black light inspection was able to detect HD-2 residues at surface densities of 8 and $10 \mu \mathrm{g} / \mathrm{cm}^{2}$, but not at $1 \mu \mathrm{g} / \mathrm{cm}^{2}$. The CAU successfully detected $1 \mathrm{~g} / \mathrm{cm}^{2}$ of HD-2 grease on a stainless steel plate.

Yellow Tape Adhesive: Black light inspection attempted to detect yellow tape adhesive residue on stainless steel plates, at residues concentrations of $1,5,10,20$, and $50 \mu \mathrm{g} / \mathrm{cm} .{ }^{2}$ No residue was detected with the black light at these concentrations. Black light inspection did detect yellow tape residue at a concentration of $100 \mu \mathrm{g} / \mathrm{cm} .^{2}$ The $C A U$ detected yellow tape adhesive residue at a concentration of $1 \mathrm{~g} / \mathrm{cm}^{2}$ on a stainless steel plate.

\section{Task 7: CAU Viability During Routine Manufacturing Operations}

A demonstration of the CAU was conducted at the Thiokol facility in August 2000 on full-scale RSRM hardware. CAU capabilities were compared to the current method of surface analysis called an FTIR wipe, which entails wiping a surface and performing IR analysis of the extract from wipers. CAU capabilities were demonstrated on a baremetal case as well as on witness panels with a known amount of grease. Calibration possibly suffered due to transportation. Grease on the test panel was detected, but the concentration measured with the CAU was lower than the gravimetrically determined quantity of grease.

The CAU was also demonstrated on cured NBR insulation. The CAU was able to draw a vacuum and read background signals from the insulation, suggesting that its vacuum might be able to pull absorbed contaminants out of the matrix of the NBR at sufficient quantities to detect them in the field.

\section{Discussion of Test Results}

The gravimetrically-determined concentration of grease on the witness panel was 14.88 $\mathrm{mg} / \mathrm{ft}^{2}$. The CAU estimated $4 \mathrm{mg} / \mathrm{ft}^{2}$. This was determined using a calibration curve that was four months old and, perhaps more importantly, generated before the CAU was taken apart, transported to Utah, and reassembled. CAU measurements taken within a week of calibration have been shown to remain very close to the actual concentration of the contaminant, if the CAU is not disassembled and reassembled (see Table 6). In all cases. the data collected on the same day that the CAU was calibrated and the data that was collected a week later show that measured and applied HD-2 grease concentrations were comparable.

\footnotetext{
"This was the average surface concentration over the dimpled sampling areas on the stainless steel plates.
} 
Table 6. Actual vs. CAU-measured concentrations of HD-2 grease. All CAU-measured

HD-2 grease concentrations were calculated using the calibration curve generated on 5/5/2000.

\begin{tabular}{|c|c|c|c|c|}
\hline Date & Location & $\begin{array}{c}\text { Integrated } \\
\text { Area }\end{array}$ & $\begin{array}{c}\text { HD-2 applied to } \\
\text { plate }\left(\mu \mathbf{g} / \mathbf{c m}^{2}\right)\end{array}$ & $\begin{array}{c}\text { HD-2 measured } \\
\text { with CAU }\left(\mu \mathbf{g} / \mathbf{c m}^{2}\right)\end{array}$ \\
\hline $5 / 5 / 2000$ & LLNL & $9.00 \mathrm{E}-09$ & 1 & 1 \\
\hline $5 / 11 / 2000$ & LLNL & $1.00 \mathrm{E}-09$ & 0.5 & 0.5 \\
\hline $5 / 11 / 2000$ & LLNL & $7.00 \mathrm{E}-09$ & 1 & 1 \\
\hline $5 / 11 / 2000$ & LLNL & $1.00 \mathrm{E}-07$ & 10 & 10 \\
\hline $5 / 12 / 2000$ & LLNL & $9.00 \mathrm{E}-10$ & 0.5 & 0.5 \\
\hline $5 / 12 / 2000$ & LLNL & $3.00 \mathrm{E}-09$ & 1 & 1 \\
\hline $5 / 12 / 2000$ & LLNL & $9.00 \mathrm{E}-08$ & 10 & 9 \\
\hline $8 / 23 / 2000$ & Thiokol & $4.00 \mathrm{E}-08$ & 15 & 4 \\
\hline
\end{tabular}




\begin{abstract}
Appendix A
Results from Selected Ion Monitoring Runs,

Detection of Trichloroethane (TCA) and

PF Degreaser (PFD) for Prolonged Periods After

Application to NBR Insulation
\end{abstract}



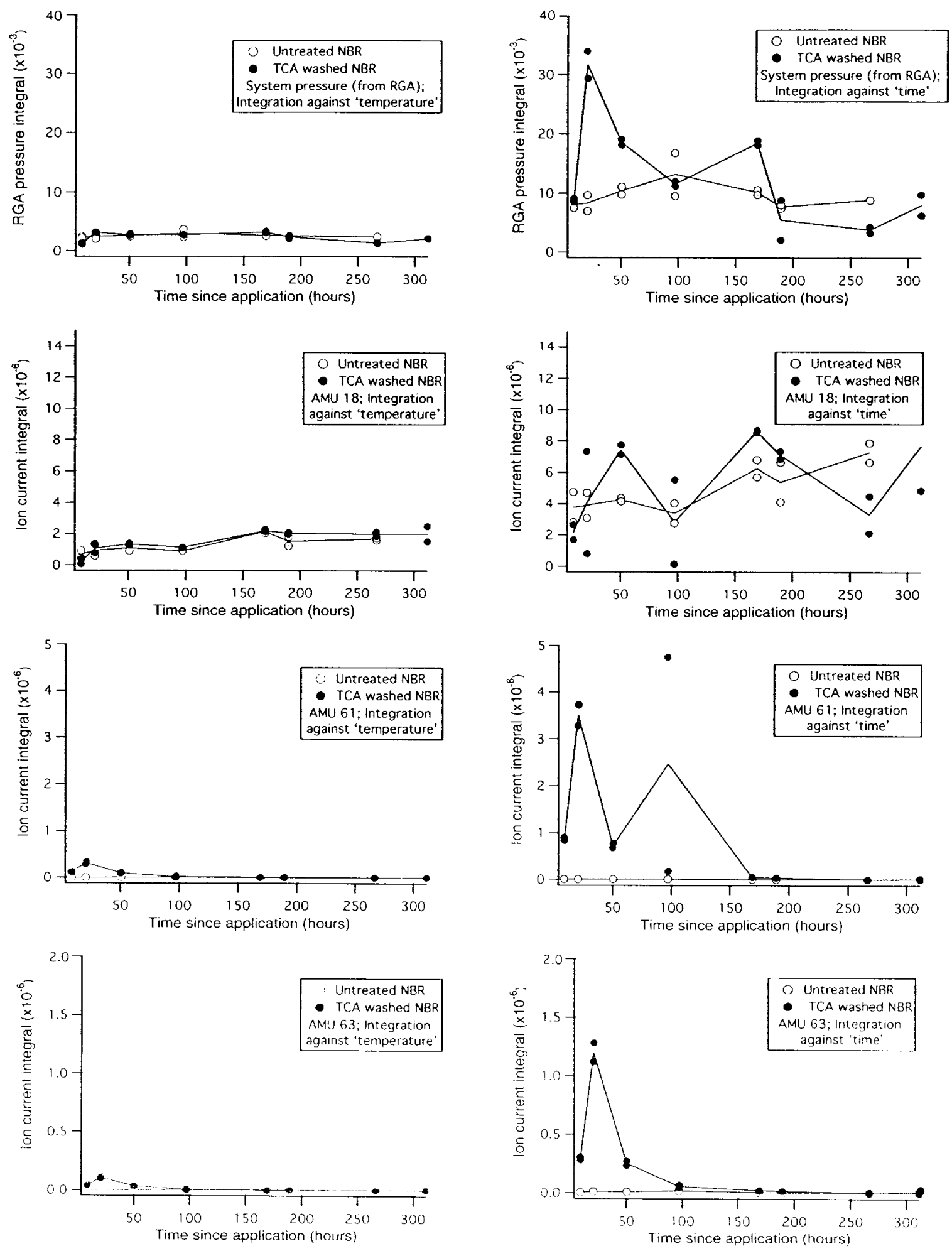

Figure A-1. CAU RGA pressure and ion current integrals with time, following application of trichloroethane (TCA) to sample NBR panels. At left are data integrated against sample temperature, and at right, integrals against time. during each desorption run. In all plots, solid symbols and lines are treated panels, open symbols and dotted lines are untreated blank NBR panels. Lines connect the means of two measurements. 

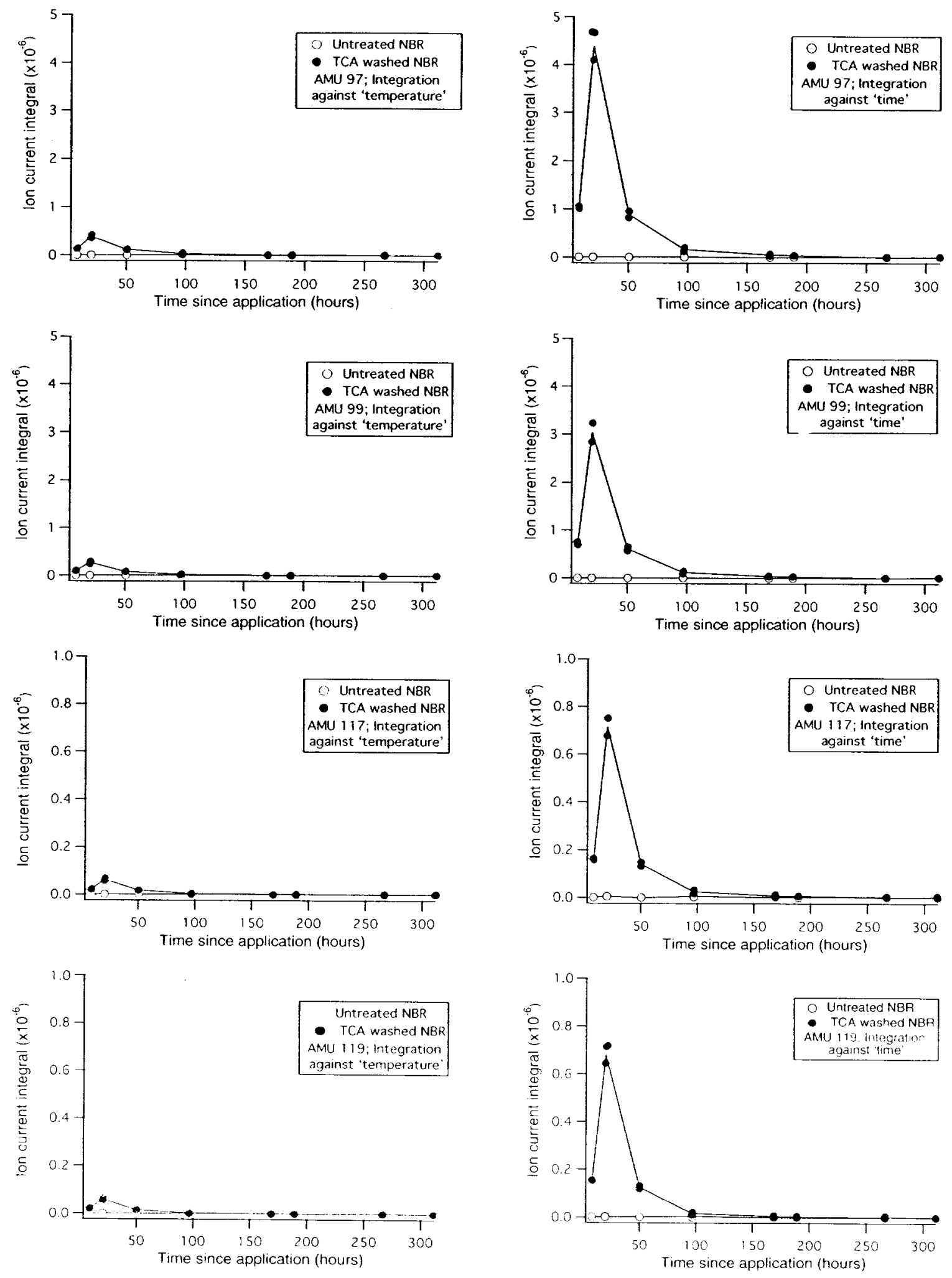

Figure A-2. CAU ion current integrals with time, following application of trichloroethane (TCA) to sample NBR panels. At left are data integrated against sample temperature, and at right, integrals against time. 

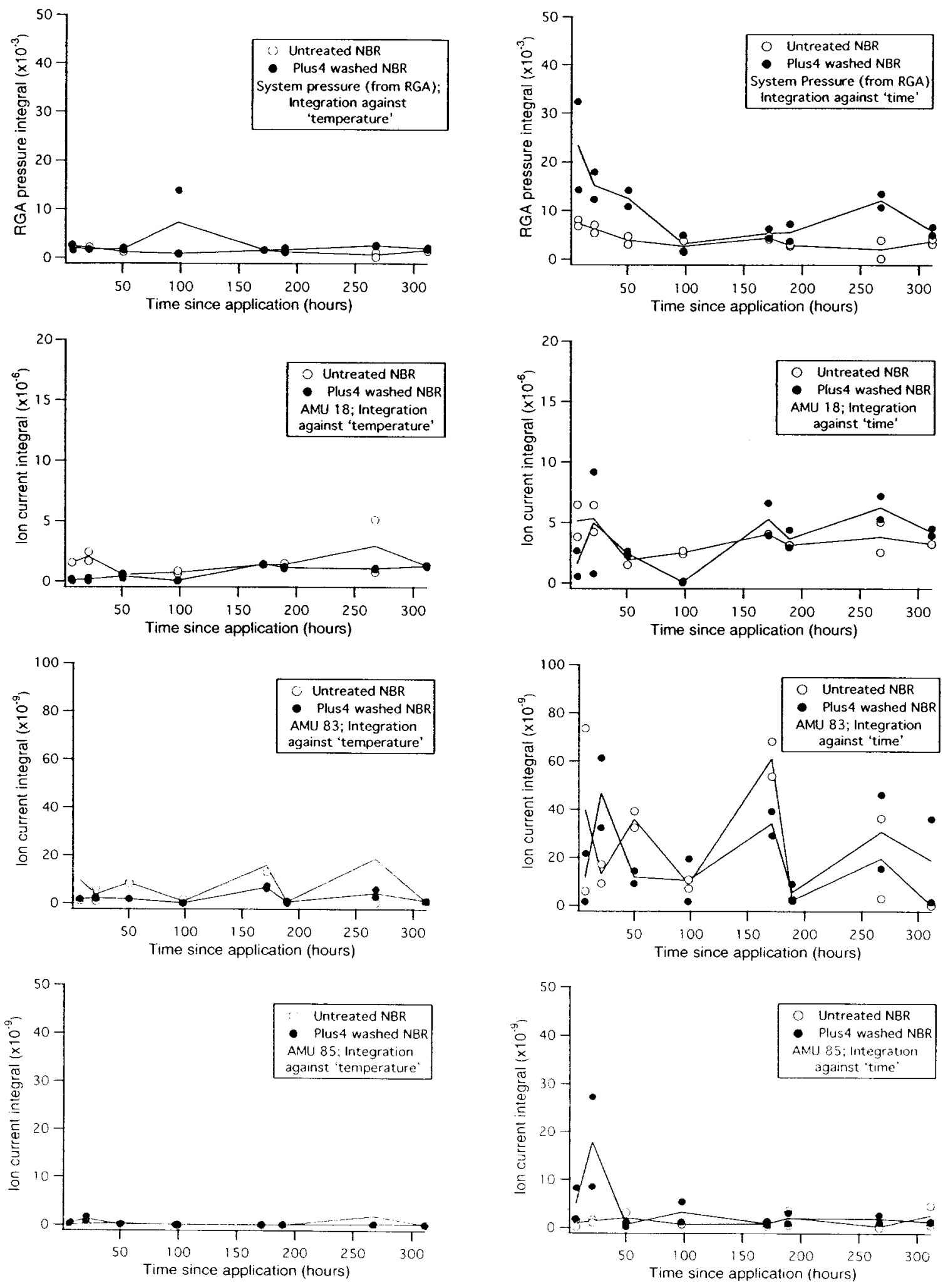

Figure A-3. CAU RGA pressure and ion curtent integrals with time, following application of PF Degreaser to sample NBR panels. At left are data integrated against sample temperature, and at right, integrals against time. during each desorption run. In all plots. solid symbols and lines are treated panels, open symbols and dotted lines are untreated blank NBR panels. Lines connect the means of two measurements. 

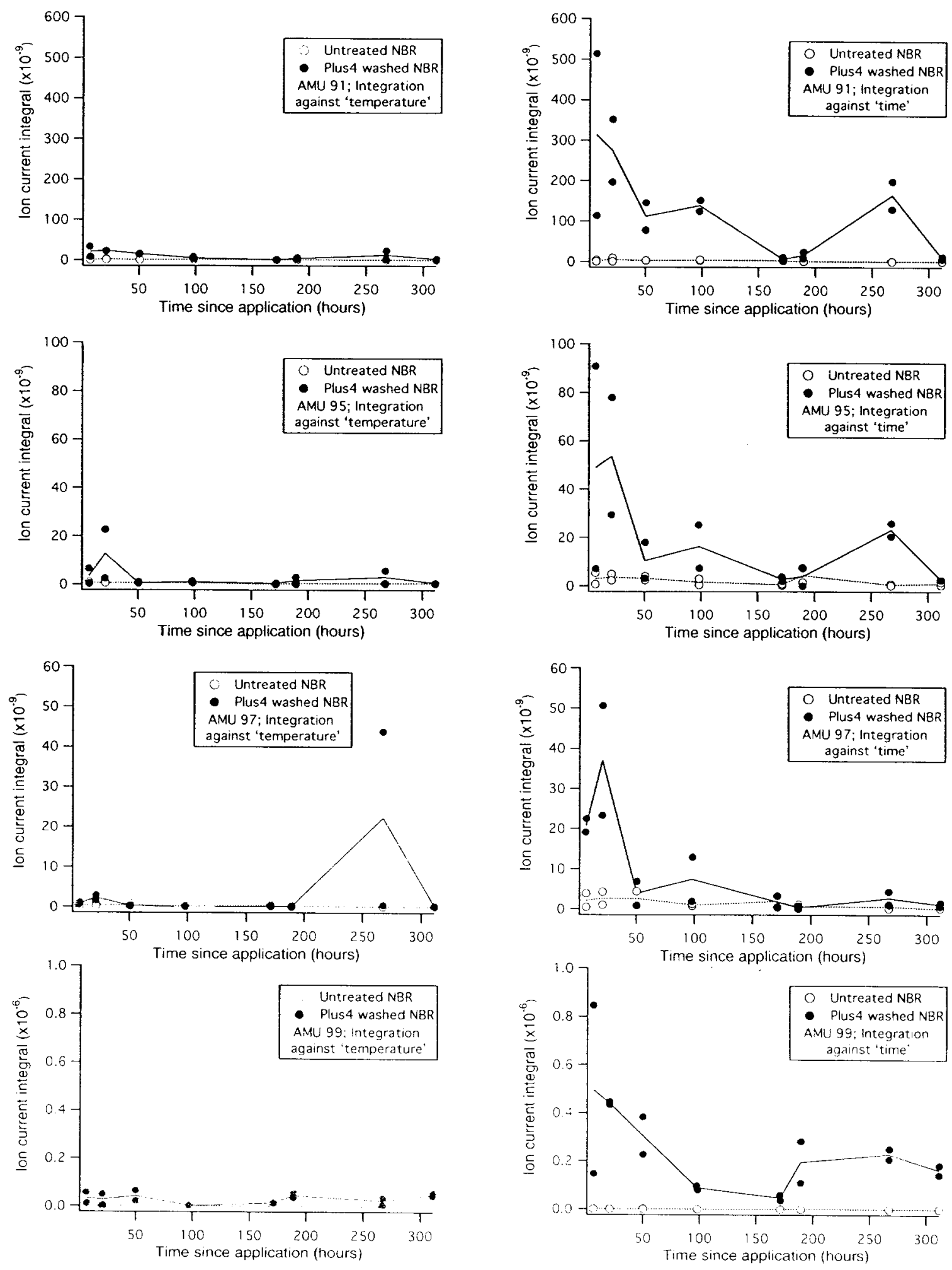

Figure A-4. CAU ion current integrals with time, following application of PF Degreaser to sample NBR panels. At left are data integrated against sample temperature, and at right, integrals against time, during each desorption run. In all plots, solid symbols and lines are treated panels, open symbols and dotted lines are untrealed blank NBR panels. Lines connect the means of two measurenents. 

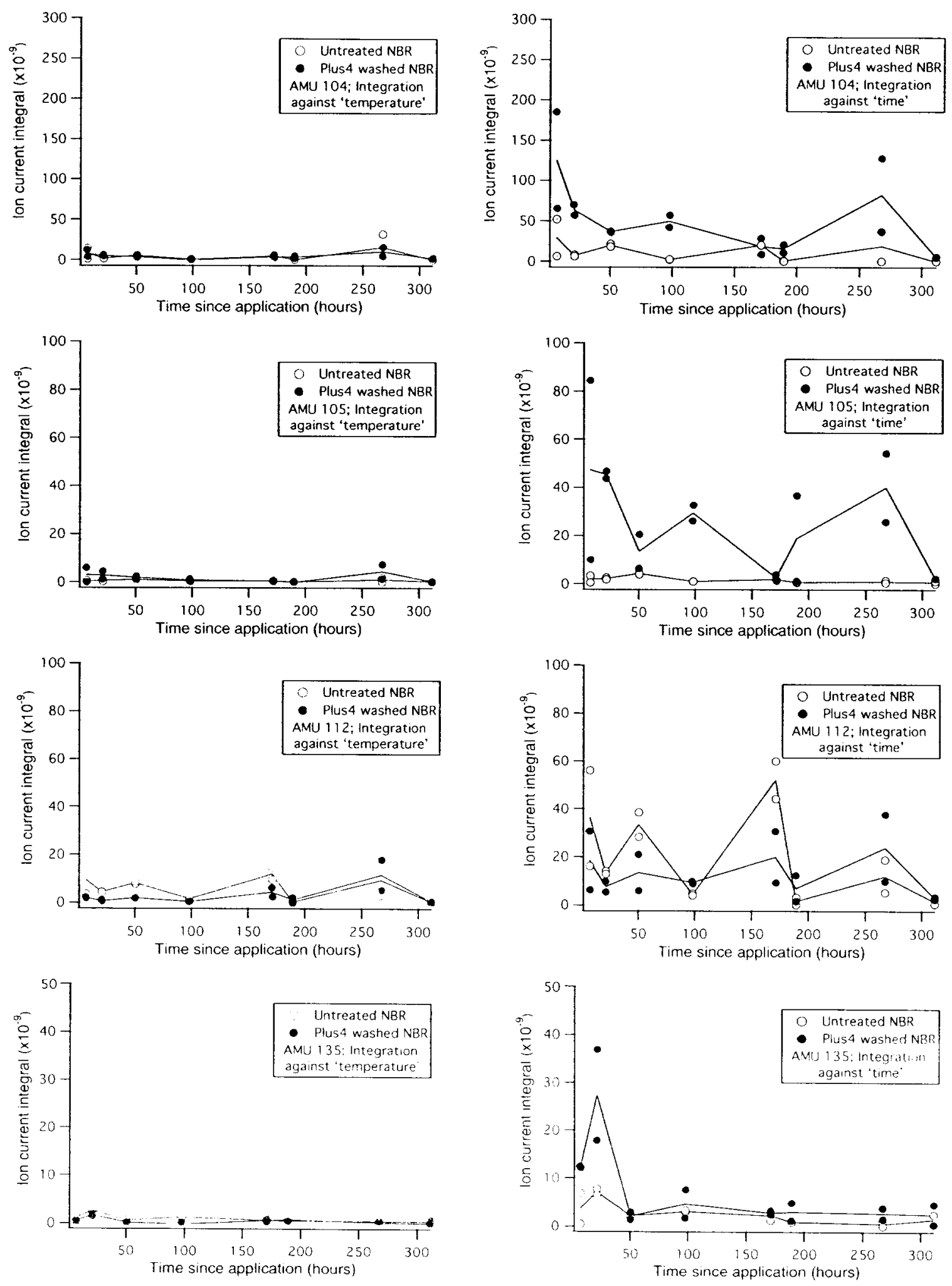

Figure A-5. CAU ion current integrals with time, following application of PF degreaser to sample NBR panels At left are data integrated against sample temperature, and at right, integrals against time. during cach desorption run. 


\section{Appendix B}

Results from Selected Ion Monitoring Runs, Illustrating the Effect of Differing Integration Methods 

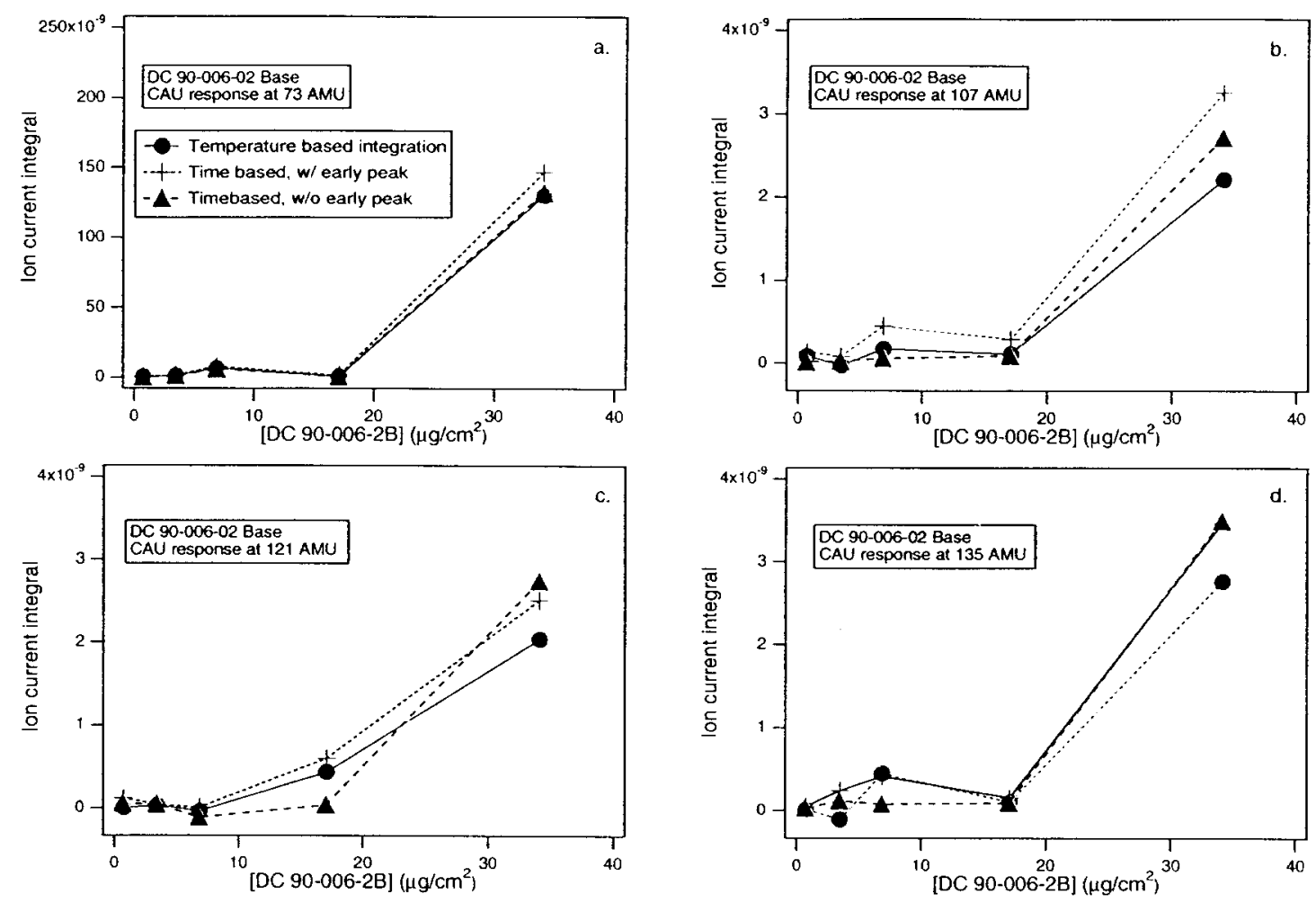

Figure B-1. Ion current integrals versus area corrected contaminant concentration for thermal desorption experiment with DC 90-006-02 (Base). Note that the three types of integrations (temperature based integration, and time based integrations with and without inclusion of early peak) all produce very similar results. 

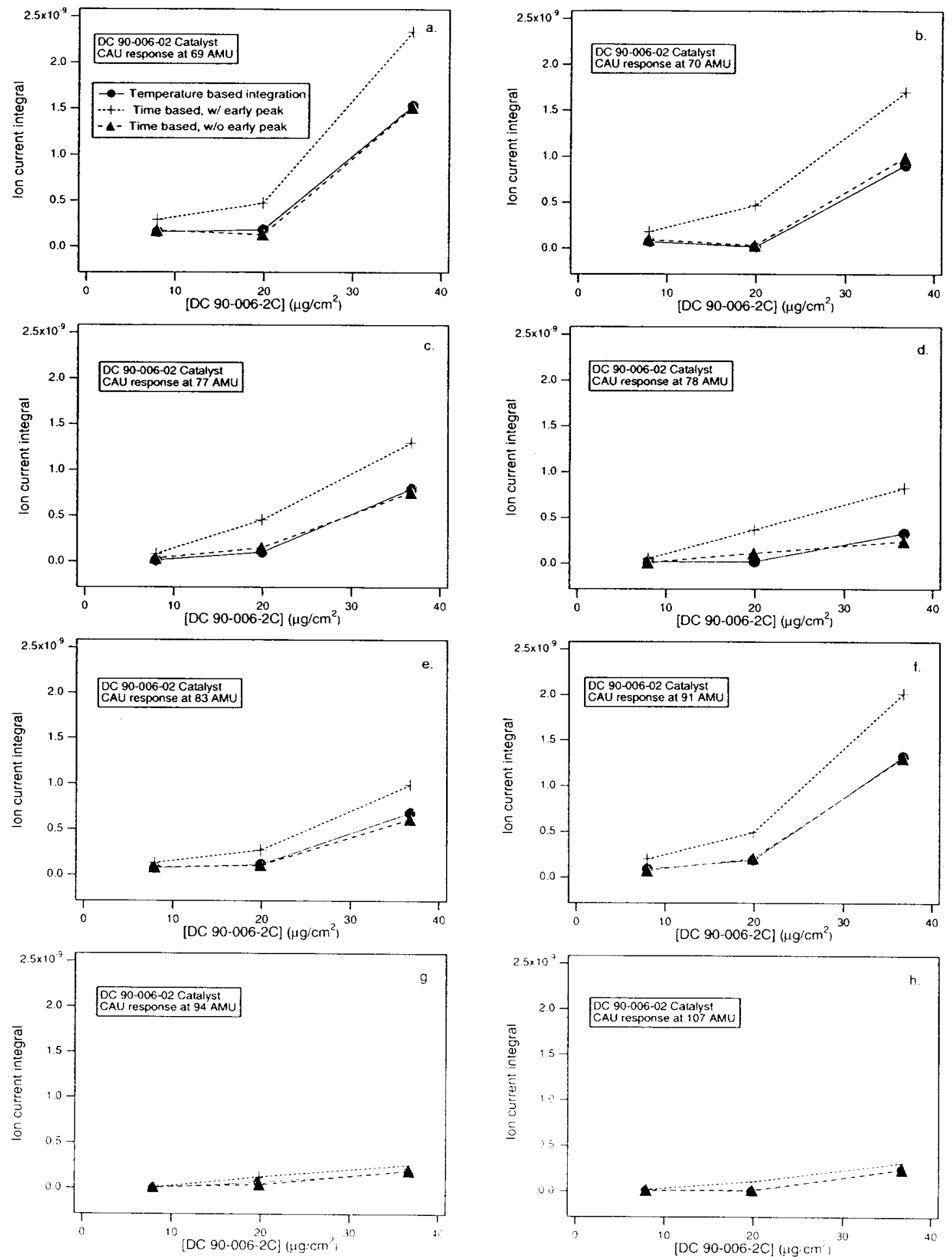

Figure B-2. Ion current integrals versus area corrected contaminant concentration tor thernal desorption experiment with DC 90-006-02 (Catalyst). Note that in a-f integration including the early peak generates a noticeably higher ion current than integrations that exclude the early peak. This may indicate that greater CAL sensitivity can. in some cases, be attained through inclusion of the early peak. 

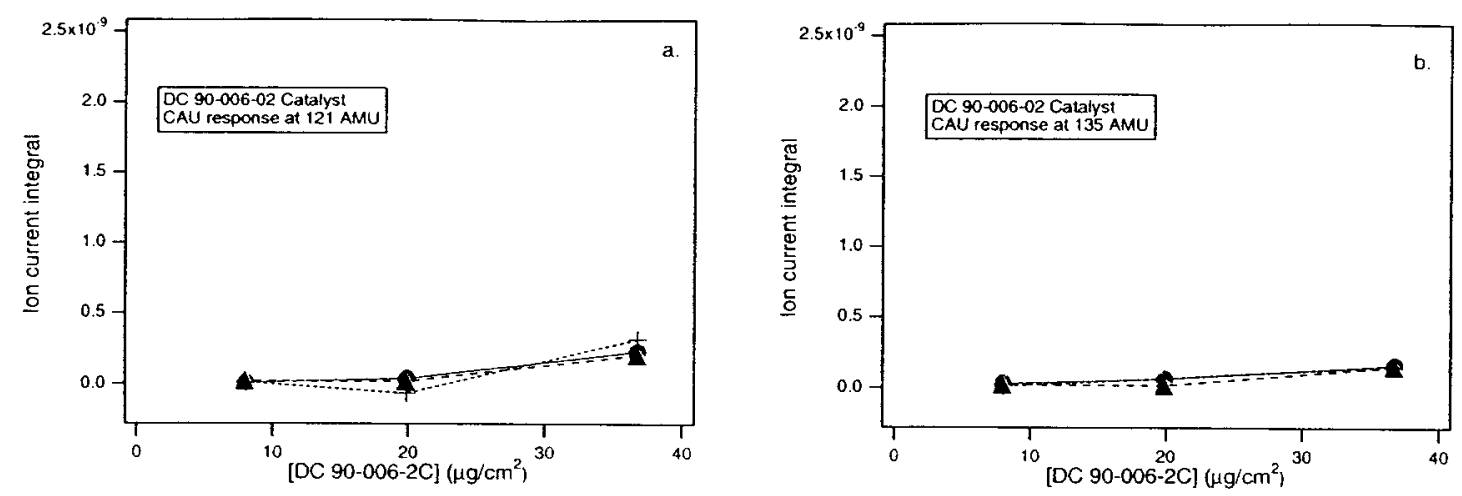

Figure B-3. Ion current integrals versus area corrected contaminant concentration for thermal desorption experiment with DC 90-006-02 (Catalyst). Note that ion current integrations do not vary significantly with different integration methods. 

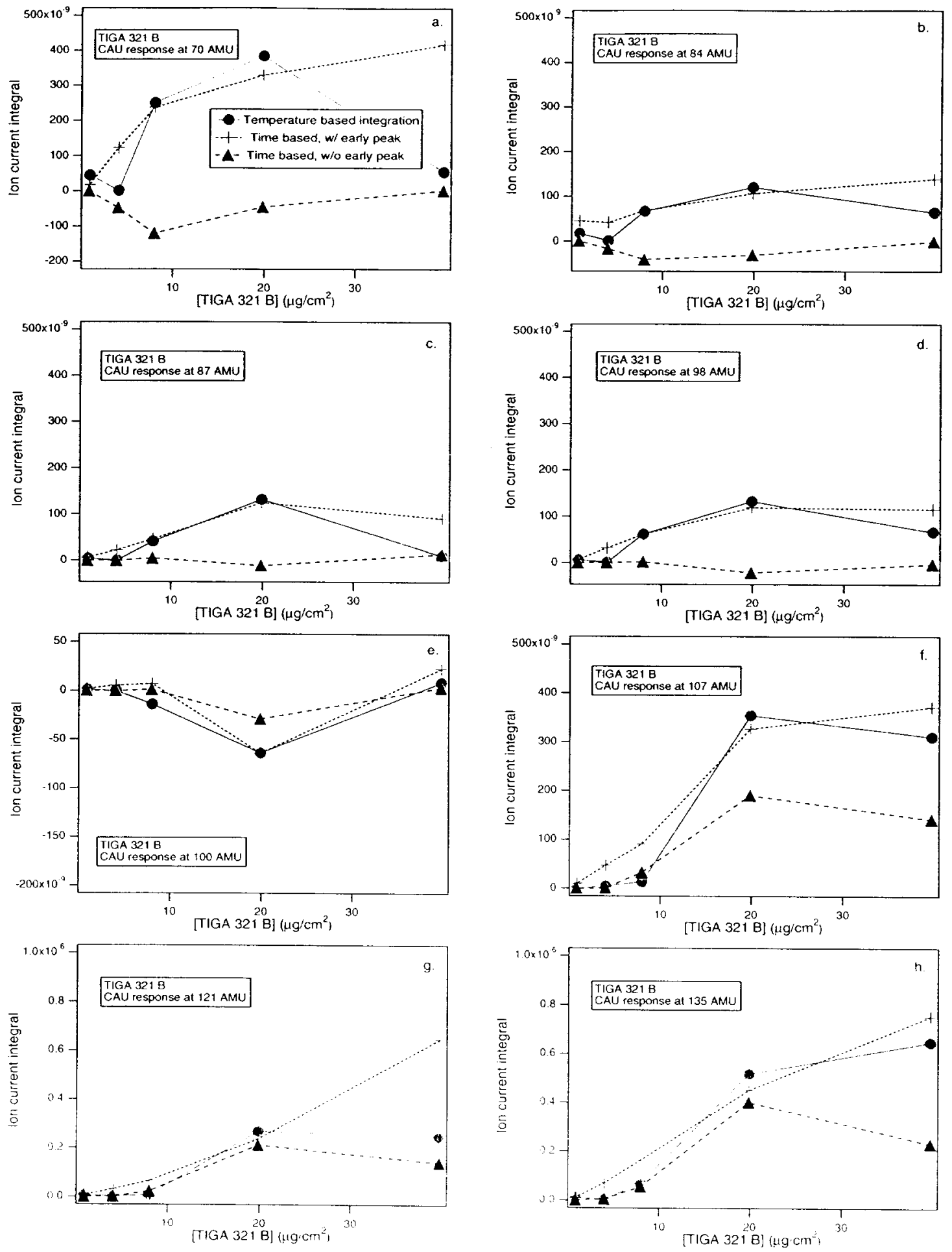

Figure B-4 lon current integrals versus area corrected contaminant concentration for thermal desorption experiment with TIGA $321 \mathrm{~B}$. 

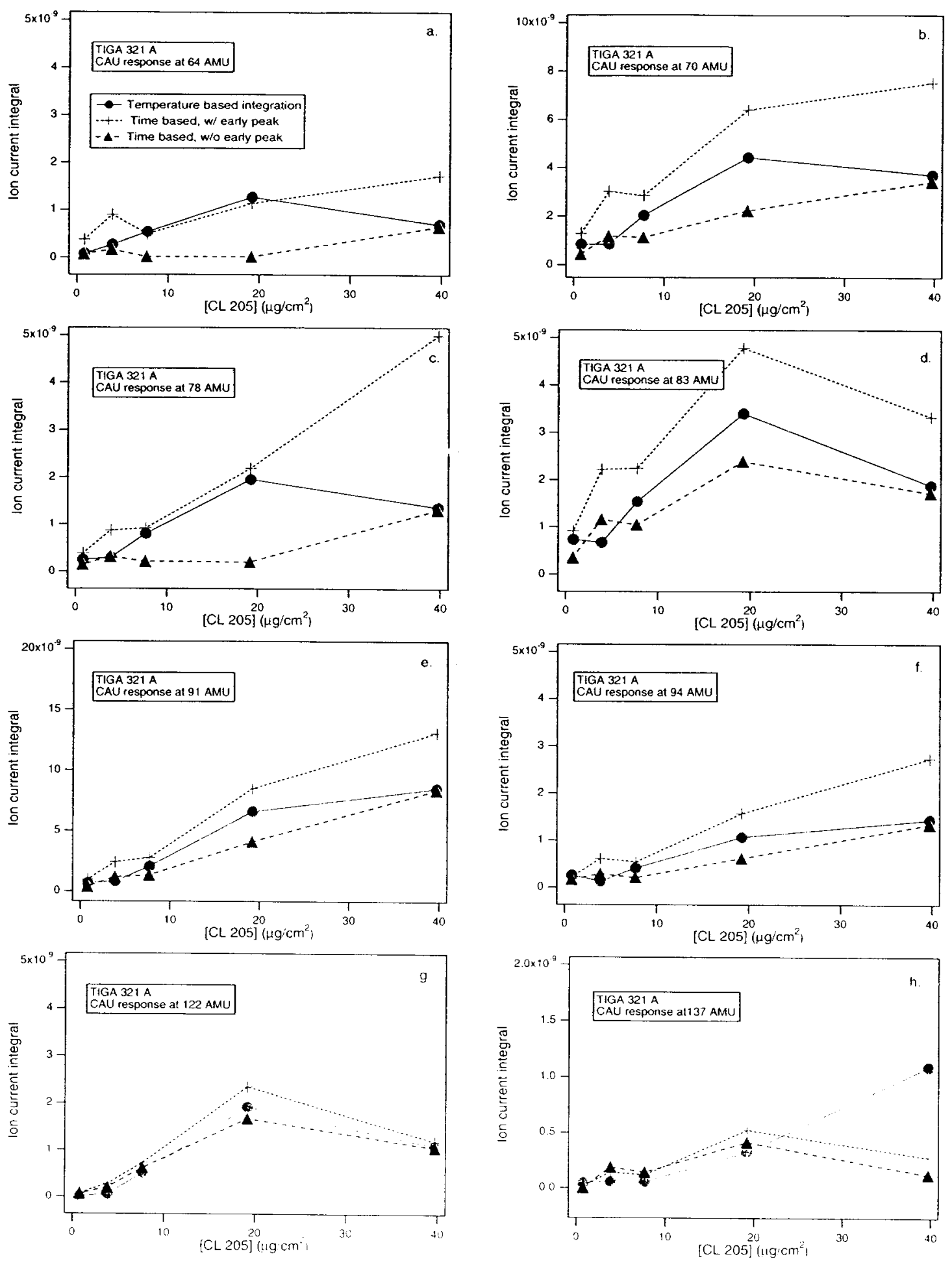

Figure B-5. Ion current integrals versus area corrected contaminant concentration for thermal desorption experiment with TIGA $321 \mathrm{~A}$. 

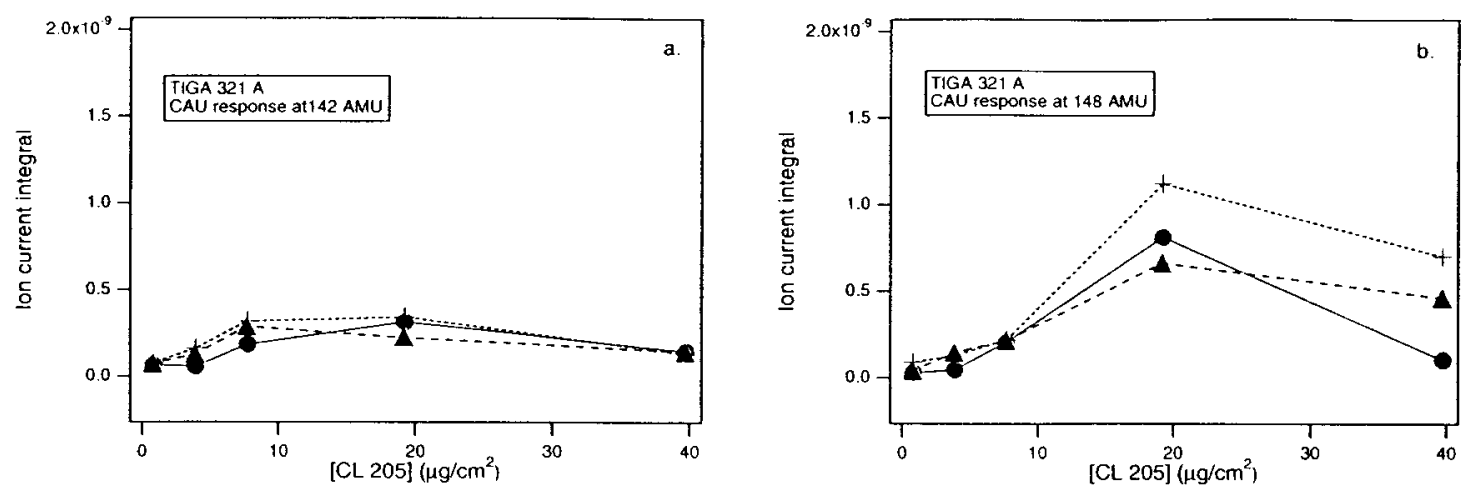

Figure B-6. Ion current integrals versus area corrected contaminant concentration for thermal desorption experiment with TIGA $321 \mathrm{~A}$. Note that in case $\mathrm{b}$, integration including the early peak generates a noticeably higher ion current than integrations that exclude the early peak. In case a, the three types of signal integrations all produce very similar results. These results suggest that in some cases, greater CAU sensitivity can be attained through inclusion of the eariy peak. 

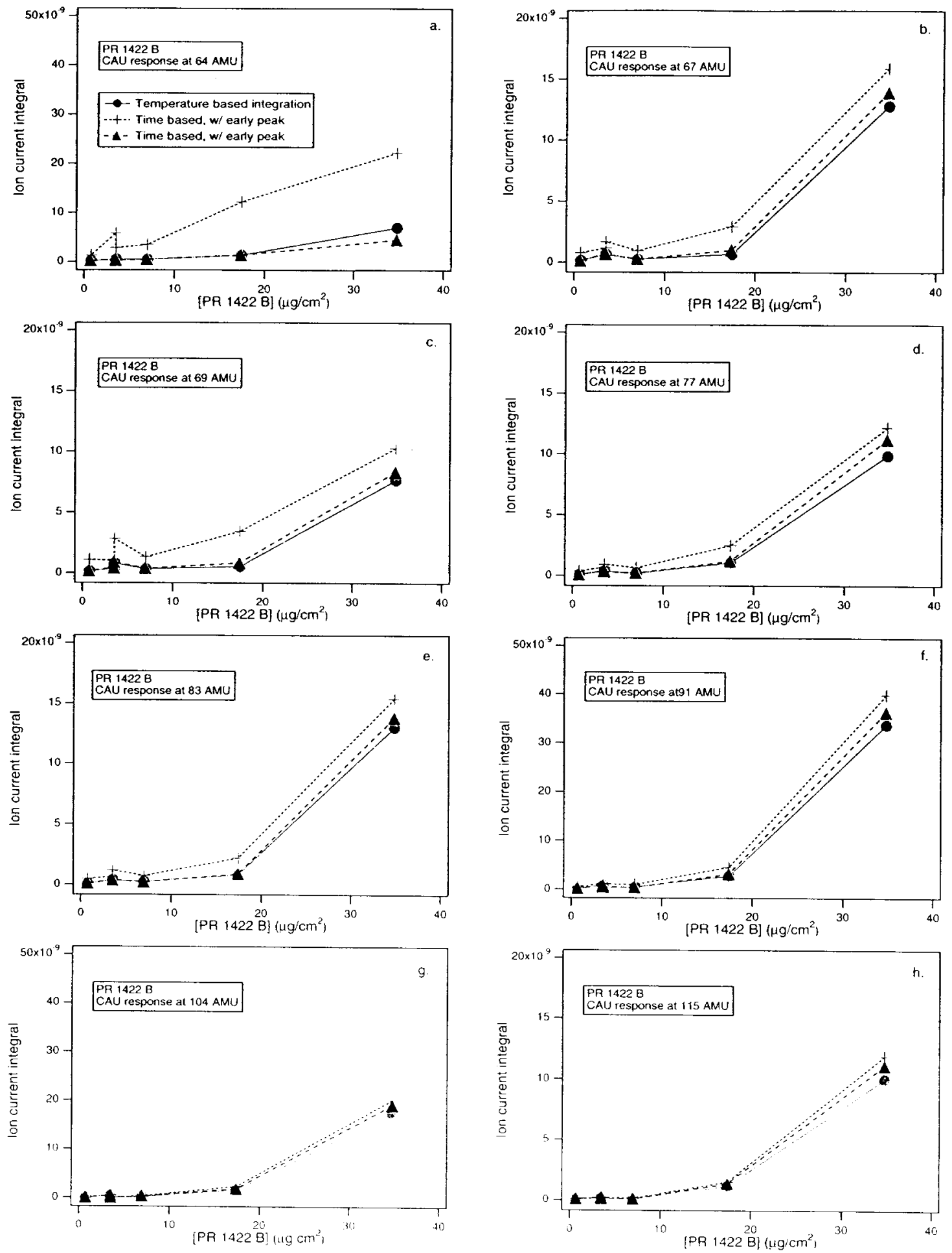

Figure B-7. Ion current integrals versus area corrected contaminant concentration for thermal desorption experiment with PR $1422 \mathrm{~B}$. 

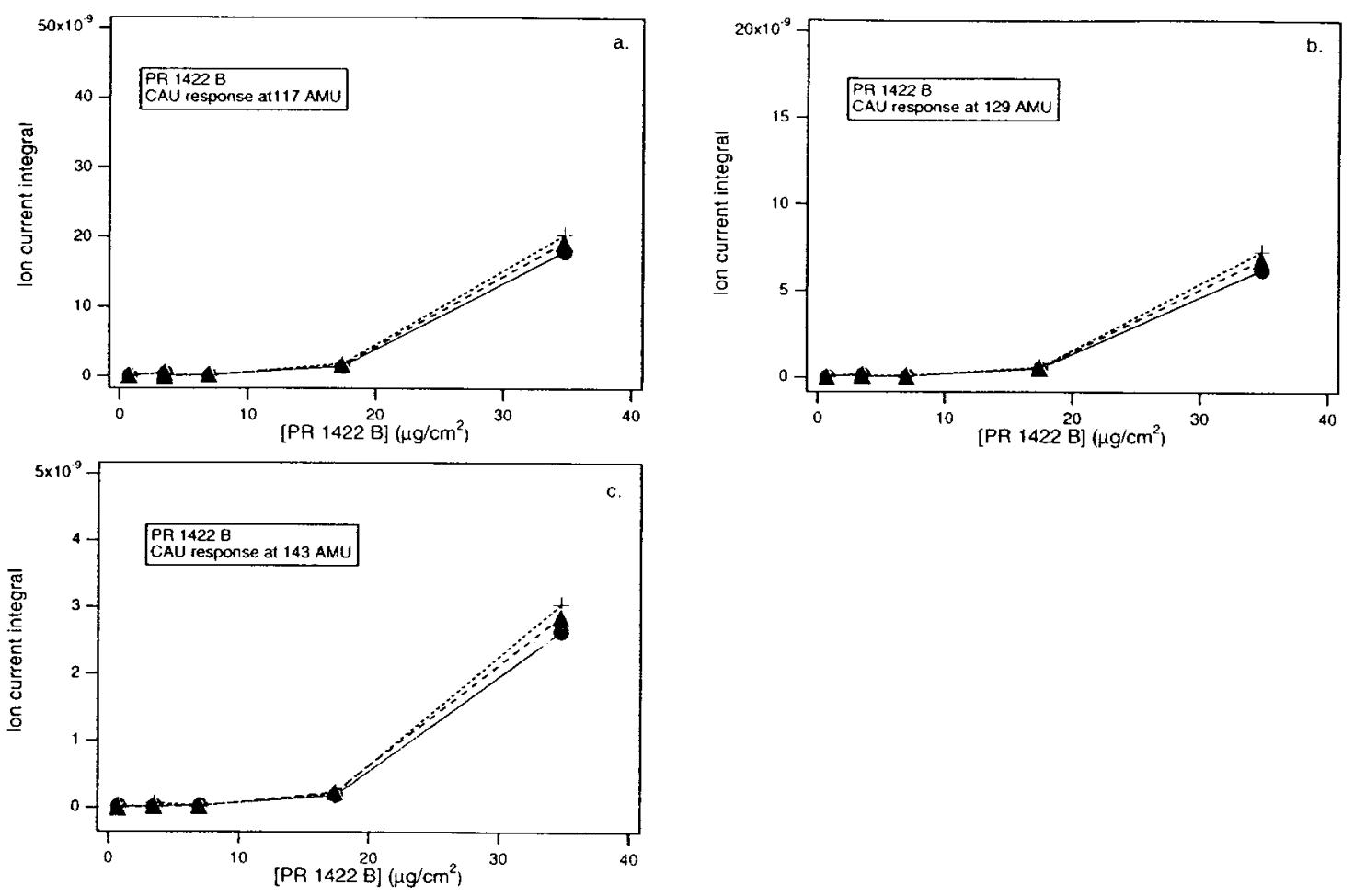

Figure B-8. Ion current integrals versus area corrected contaminant concentration for thermal desorption experiment with PR 1422B. Note that ion current integrations do not vary significantly with different integration methods. 

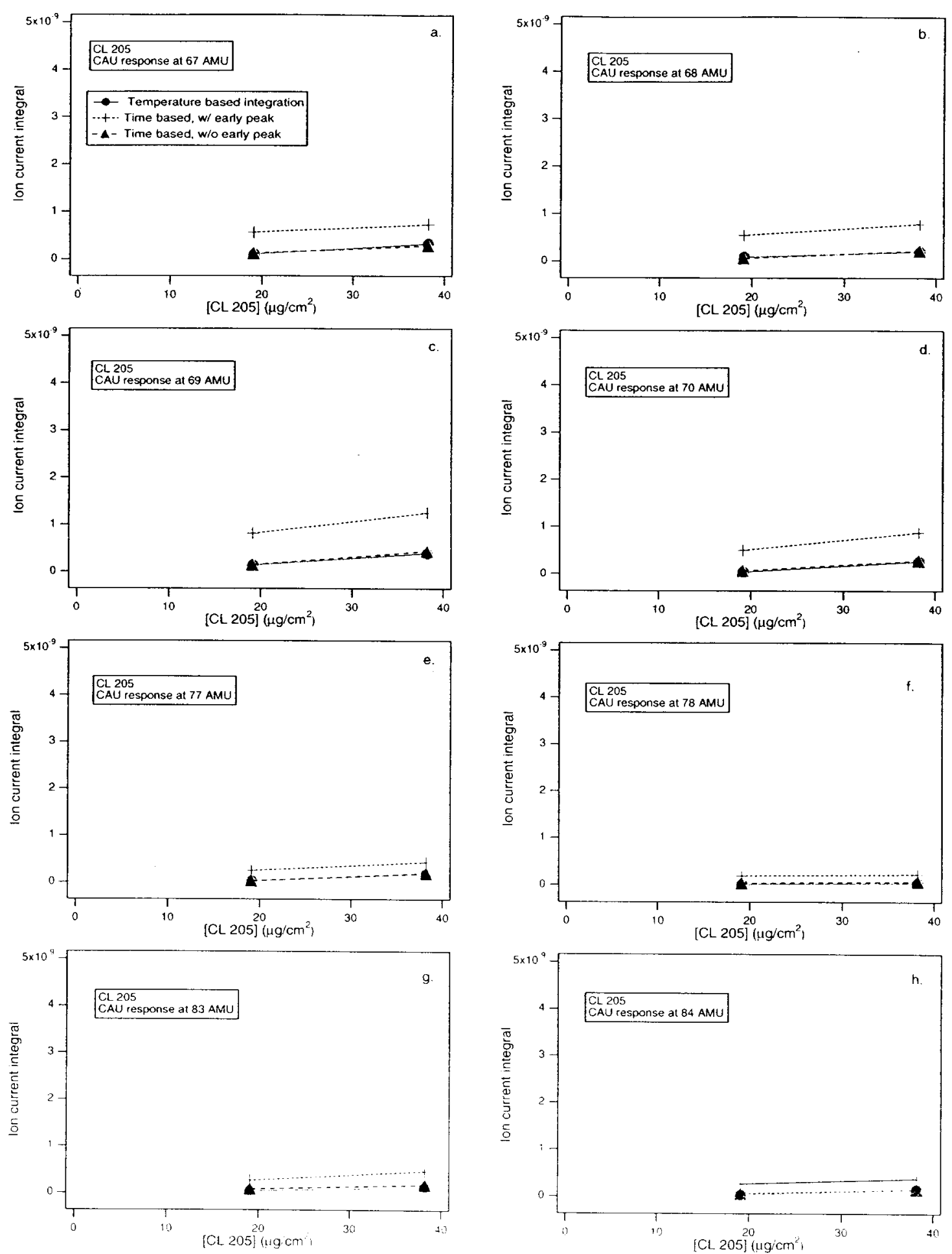

Figure B-9. Ion current integrals versus area-corrected contaminant concentration for thermal desorption experiment with CL 205. Note that in cases a-d, integration inc/uding the early peak generates a noticeably higher ion current than integrations that exclude the early peak. This may indicate that greater CAU sensitivity can, in some cases, be attained through inclusion of the early peak. 

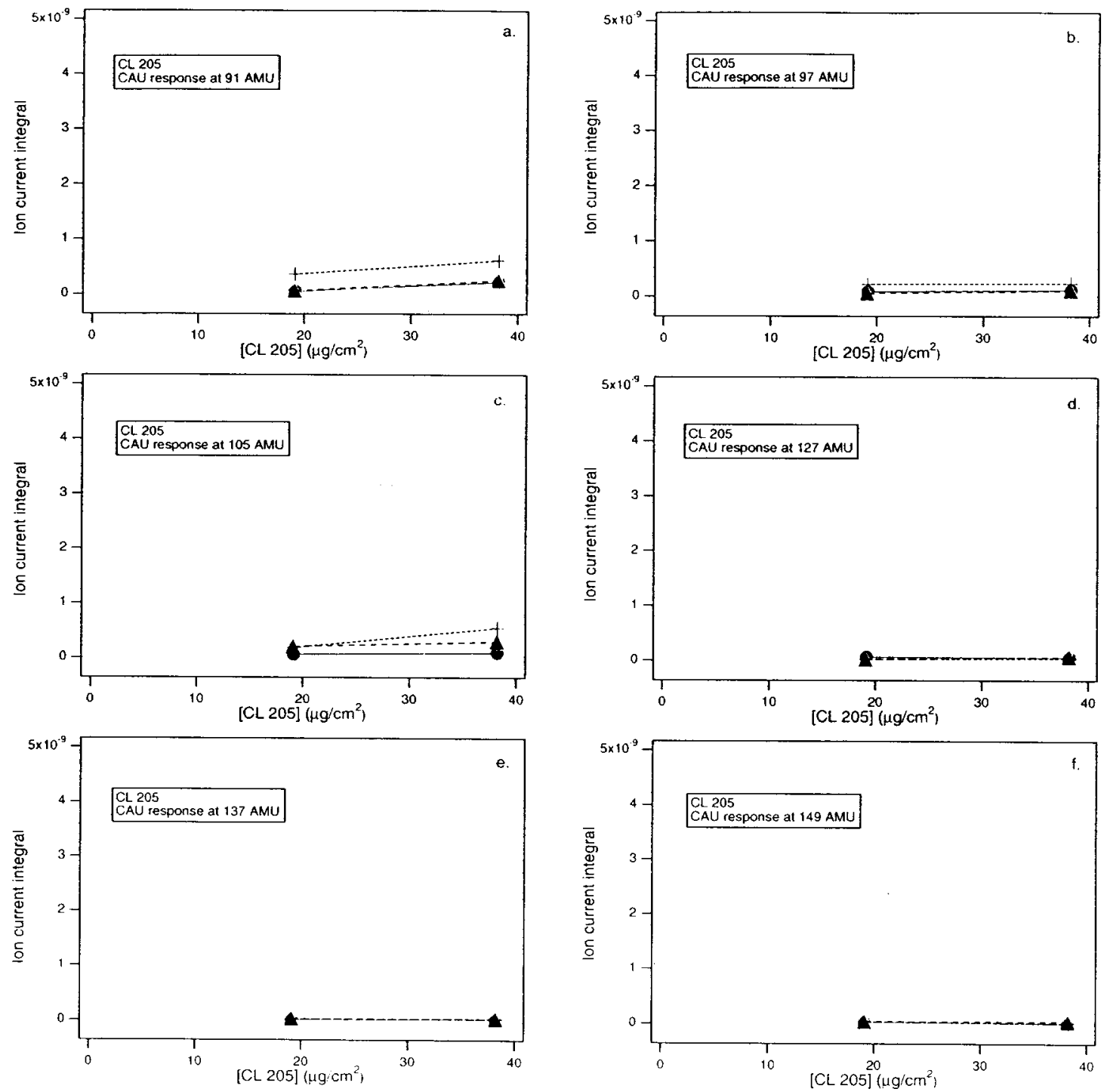

Figure B-10. Ion current integrals versus area corrected contaminant concentration for thermal desorption experiment with CL 205 